\title{
An Emerging Role for Serine Protease Inhibitors in T Lymphocyte Immunity and Beyond
}

\author{
Philip G. Ashton-Rickardt \\ Section of Immunobiology, Division of Immunology and Inflammation, Department of Medicine, Faculty of Medicine, \\ Imperial College London, Sir Alexander Fleming Building, Room 258, Exhibition Road, South Kensington, London SW7 2AZ, UK \\ Correspondence should be addressed to Philip G. Ashton-Rickardt, p.ashton-rickardt@imperial.ac.uk
}

Received 29 July 2012; Accepted 6 September 2012

Academic Editors: G. Chaouat, P. Kisielow, A. Sundstedt, and A. Vicente

Copyright ( 2012 Philip G. Ashton-Rickardt. This is an open access article distributed under the Creative Commons Attribution License, which permits unrestricted use, distribution, and reproduction in any medium, provided the original work is properly cited.

\begin{abstract}
The serine proteases of T lymphocytes provide immunity to infection. Serine Proteases Inhibitors (serpins) control the recognition of antigen, effector function, and homeostatic control of T lymphocytes through the inhibition of serine protease targets. Serpins are important promoters of cellular viability through their inhibition of executioner proteases, which affects the survival and development of long-lived memory $\mathrm{T}$ cells. The potent antiapoptotic properties of serpins can also work against cellular immunity by protecting viruses and tumors from eradication by $\mathrm{T}$ lymphocytes. Recent insights from knockout mouse models demonstrate that serpins also are required for hematological progenitor cells and so are critical for the development of lineages other than $\mathrm{T}$ lymphocytes. Given the emerging role of serpins in multiple aspects of lymphocyte immunity and blood development, there is much potential for new therapeutic approaches based directly on serpins or knowledge gained from identifying their physiologically relevant protease targets.
\end{abstract}

\section{Serine Protease Inhibitors}

Homeostatic regulation of serine proteases is mainly achieved through interaction with inhibitors belonging to the Serine Protease Inhibitor (serpin) superfamily [1]. Inhibitory serpins have a common mode of action: each contains a variable C-terminal reactive center loop (RCL) resembling the substrate of its cognate protease. Serpins regulate proteolytic pathways by acting as "suicide substrates" and inactivating serine proteases through the formation of a $1: 1$ complex [1] (Figure 1). On protease binding, the RCL is cleaved between the two residues designated $\mathrm{P}_{1}$ and $\mathrm{P}_{1}^{\prime}$ and it undergoes a conformational change that distorts the protease and irreversibly locks the serpin-protease complex. Most serpins are secreted and constitute about $10 \%$ of plasma proteins. In vertebrates, clade B serpins belong to a large intracellular family [2]. The intracellular serpins (serpin IC) lack cleavable $\mathrm{N}$-terminal signal peptides and dwell within the nucleocytoplasmic compartment. Serpins IC inhibit several key proteases that trigger cell death and so there is an emerging view that they are key regulators of cell survival.
In addition to inhibiting serine proteases, some serpins $s_{\text {IC }}$ are cross-class-specific and inhibit cysteine proteases. The serpin $_{\text {IC }}$ cytokine response modifier A (CrmA) from the cowpox virus and SERPINB9 (PI9) from humans can inhibit caspases [3-6]. Cross-class-specific serpins IC $_{\text {also inhibit }}$ papain-like, lysosomal cysteine cathepsins, such as cathepsin B, V, L, K, and H. For example, Serine Protease Inhibitor 2A (Spi2A) (Serpina3g) from mice inhibits the serine protease cathepsin $\mathrm{G}$ and also papain-like, lysosomal cysteine cathepsins such as cathepsin B, V, L, K, and $\mathrm{H}$ [7]. This cross-class specificity of Spi2A for cysteine cathepsins is also a property of another mouse serpin SQN-5 (Serpinb3a) and the human serpin SCCA1 (SERPINB3) $[8,9]$. The general evolutionary relevance of cross-class-specific serpin ${ }_{\text {IC }}$ is illustrated by SRP-6, which inhibits lysosomal cysteine cathepsins in Caenorhabditis elegans [10]. The mechanism by which cysteine proteases are inhibited involves the cleavage of the serpin $_{I C}$, in some cases involving a stable covalent complex $[3,4,8,10]$ and in other cases not $[3,7]$. Cellular inhibitors of apoptosis (c-IAPs) [11] are physiological inhibitors of caspases and cystatins inhibit papain-like cysteine cathepsins 


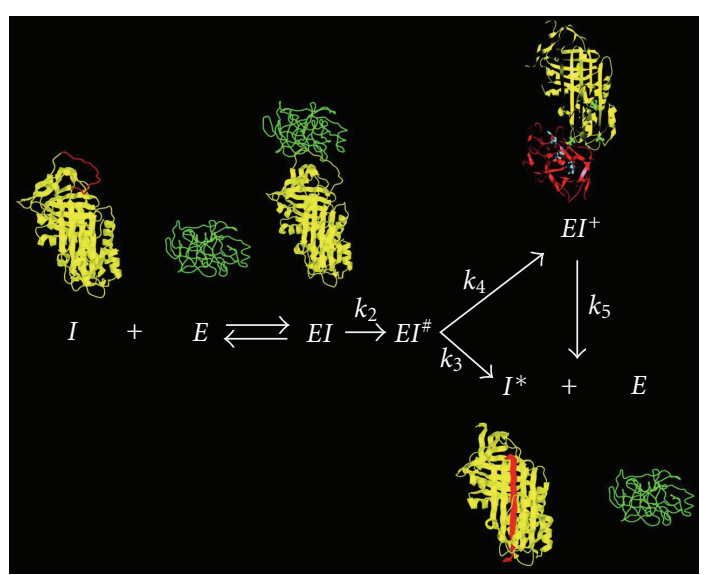

Figure 1: Serpin mechanism of action. Fate of the serpin and proteinase complex via the branched pathway. The serpin (I) inhibition of proteinase $(E)$ proceeds via an initial noncovalent, Michaelis-like complex (EI) that involves no conformational change within the proteinase or the body of the serpin. Subsequent peptide bond hydrolysis results in an acyl-enzyme intermediate $\left(E I^{\#}\right)$ that progresses to either a kinetically trapped loop-inserted covalent complex $\left(E \mathrm{I}^{+}\right.$, inhibitory pathway) or a cleaved serpin ( $\left.\mathrm{I}^{*}\right)$ and free proteinase (noninhibitory or substrate pathway). The serpin body is in yellow. Free serine proteinase is in green and covalently bound proteinase is in red. Reprinted with permission from Cold Spring Harbor Laboratory.

[12]. However, these inhibitors do not act like suicide substrates, as do serpins, but rather inactivate by high affinity noncovalent binding. Therefore, cross-class-specific inhibition by $\operatorname{serpin}_{\mathrm{IC}}$ is a mechanism that therefore has evolved along together with other molecular inhibitors to control cysteine protease activity.

\section{Programmed Cell Death}

Programmed cell death (PCD) is defined as an active process that is dependent on signaling processes within the dying cell [13]. Morphological criteria can be used to divide PCD, into three subclasses: classic apoptosis, apoptosislike PCD and necrosis-like PCD [13]. All three forms of death involve the activity of executioner serine proteases, caspases, and cysteine proteases. In apoptosis, chromatin condenses to compact and apparently discrete geometric figures; in contrast apoptosis-like PCD is characterized by less-compact, lumpy chromatin masses [13]. Both forms of apoptosis usually require mitochondrial outer membrane permeabilization, which is controlled by the Bcl-2 family of proteins and the release of AIF, cytochrome $c$, and Smac-a/Diablo [14]. Necrosis-like PCD occurs either in the complete absence of chromatin condensation or at best with chromatin clustering to form loose speckles [13]. Autophagy, which is characterized by the formation of large lysosome-derived cytosolic vacuoles, and death-receptorinduced necrotic death are examples of active death programs that lack chromatin condensation and are classified as necrosis-like PCDs [13]. Although the morphology of necrosis-like PCD is indistinguishable from that of cells dying from accidental necrosis, the former is the result of active cellular processes that rely on Reactive Oxygen Species (ROS) [15-17], poly (ADP) ribose polymerase [18], autophagolysosome formation [19], and cathepsins [20].

There is a large overlap between the biochemical pathways leading to different forms of PCD, which is reflected in the executioner proteases involved (Figure 2). Serine proteases, such as granzyme $\mathrm{B}(\mathrm{GrB})$ and granzyme $\mathrm{A}$, can trigger all three morphological forms of PCD [21]. Caspases on the other hand are usually associated with either classical apoptosis or apoptosis-like PCD [22] and are activated after stimulation of death receptors (e.g., caspase 8 ) or by the release of proteins from damaged mitochondria (e.g., caspase 9) [14]. Lysosomal cathepsins, when released into the cytoplasm, trigger a spectrum of PCD morphologies, ranging from necrosis-like autophagy to classical apoptosis [23]. Cathepsins, especially the cysteine cathepsins B and L and the aspartyl cathepsin D, participate in both caspase-dependent and caspase-independent PCD induced by several stimuli, including death receptors of the Tumor Necrosis Factor Receptor (TNFR) family [24], B-cell receptors [25], T-cell receptor (TCR) [26], the p53 tumor suppressor protein [27], and ROS [28]. Depending on the cell type and the stimuli, cathepsins may function upstream [24, 29], or downstream of caspases [30,31], or even in the absence of caspase activity [30]. The relative amount of cathepsin released into the cytoplasm after lysosomal membrane permeabilization (LMP) is thought to determine whether PCD is necrotic or apoptotic (Figure 2). Low level leakage of cathepsins triggers mitochondrial permeabilization and apoptosis through Bid activation, whereas larger scale lysosomal rupture triggers necrotic PCD [23]. Since serpins IC can inhibit all three classes of executioner proteases the potential exists for them to protect from not only classical apoptosis, but also apoptosislike PCD or necrosis-like PCD.

\section{Serpins and Programmed Cell Death}

All forms of cell death require the activity of proteases and serpin $_{\text {IC }}$ have evolved to protect cells from cell death by not only inhibiting serine proteases but also other executioner proteases. The first description of an antiapoptotic function of serpin ${ }_{I C}$ comes from work on CrmA from the cowpox virus. CrmA inhibits the serine protease $\mathrm{GrB}$, which is used by $\mathrm{T}$ lymphocytes to kill infected cells. [3-6]. Mammalian serpins $s_{I C}$, which inhibit $\mathrm{GrB}$, have also been identified in humans-proteinase inhibitor 9 (PI9-SERPINB9) [32] and mice-Serine Proteases Inhibitor 6 (Spi6) [33]. In addition to inhibiting executioner serine proteases, some are cross-classspecific serpins $s_{I C}$ that inhibit cysteine cathepsins. CrmA can inhibit both caspases 1 and 8 at physiological rate constants, whereas only caspase 1 is inhibited efficiently by PI9 [3-6]. Cross-class-specific serpins IC can also inhibit executioner cathepsins. Spi2A from mice inhibits the serine protease cathepsin $G$ and also cysteine cathepsins such as cathepsin B, V, L, K, and $\mathrm{H}$ [7]. Spi2A protects from apoptotic PCD by inhibiting cathepsin B-mediated cleavage 


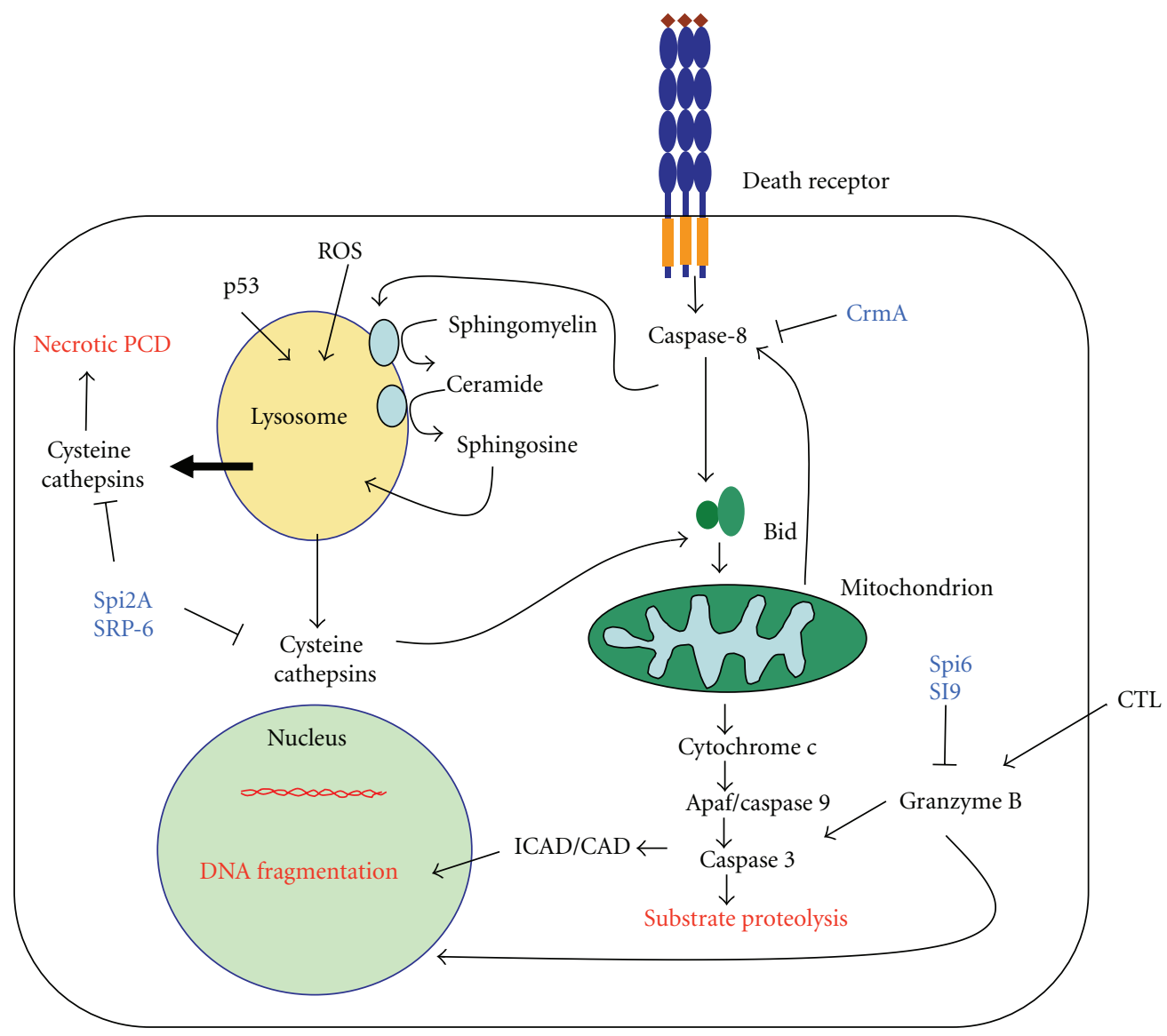

FIGURE 2: Inhibition of death pathways by serpins. Stimulation of death receptors leads to the activation of caspase 8 and the rupture of the mitochondria and release of cytochrome c, which activates the caspase 9/3 pathway of apoptosis. Multiple stimuli trigger the release of cathepsins from the lysosome into the cytoplasm. More extensive release results in necrotic PCD, whereas limited release triggers the mitochondrial pathway of apoptosis through Bid cleavage. GrB can trigger apoptotic PCD through the activation of caspase 3 or direct entry

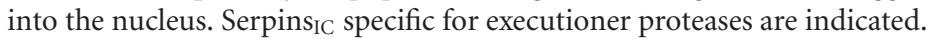

of Bid after stimulation by TNF-R1 [7] (Figure 2). Spi2A can also protect from necrotic PCD induced by ROS or TNF- $\alpha$ in the absence of caspase activity, presumably because cathepsin $\mathrm{B}$ can induce both apoptotic and necrotic PCD [34]. Spi2A is a physiological target of NF- $\kappa \mathrm{B}[7$, 35 ] and can substitute for the transcription factor in protecting cell from the lysosomal pathways of PCD [7]. The evolutionary relevance of cytoprotection by cathepsinspecific serpins IC is underlined by SRP-6, which protects in C. elegans from necrotic PCD during development [10]. SQN-5 in the mouse and the human serpin SCCA1 (SERPINB3) $[8,9]$ are other examples of cross-class-specific $\operatorname{serpin}_{\text {IC }}$ that inhibit cysteine cathepsin, but whether they are physiologically relevant inhibitors of PCD remains to be determined.

\section{Programmed Cell Death and T Lymphocytes}

Programmed cell death plays a critical role in both the antigen-independent and antigen-dependant development of T lymphocytes. Two types of cellular selection take place in the thymus to shape the repertoire of antigen specificities displayed by $\mathrm{T}$ cells. Autoreactive $\mathrm{T}$ cells are eliminated by a process referred to as negative selection through the direct induction of apoptosis [36]. Positive selection is triggered by the successful engagement of T-cell receptors (TCRs) expressed by immature thymocytes with self-major histocompatibility complex (MHC) molecules expressed on stromal cells [37]. Thymocytes that receive a signal for positive selection are rescued from apoptosis and go on to differentiate into $\mathrm{CD} 4^{+}$or $\mathrm{CD} 8^{+} \mathrm{T}$ cells [38-40]. Since only a small proportion of immature thymocytes that express TCR undergo positive selection, apoptotic death either by neglect or actively through negative selection is the most common outcome [41]. Despite the importance of PCD to early T-cell development no serpin has been implicated in determining the survival of thymocytes.

Stimulation of a naïve T-cell antigen peptide presented by self-MHC (pMHC) on the surface of dendritic cells (DC) leads to the proliferation and differentiation into effector T cells [42]. For CD4 T cells, interferon- $\gamma$-(IFN- $\gamma$-) producing $\mathrm{T}$ helper 1 (Th1) orchestrates cellular immunity to intracellular pathogens by activating macrophages and 
cytotoxic lymphocytes, whereas interleukin-4 (IL-4) and IL-5-producing Th2 cells orchestrate immunity to multicellular parasites by activating mast cells and eosinophils [43]. Antigen stimulation leads to the differentiation of CD8 T cells into cytotoxic T lymphocytes (CTLs), which directly induce the apoptosis of cells infected with intracellular pathogens [44]. After the rapid expansion in the number of antigen-specific $\mathrm{T}$ lymphocytes, which may be several orders of magnitude $[45,46]$, an equally dramatic decrease in cell number occurs [47]. This so-called contraction phase in the immune response is driven by PCD and is an important homeostatic mechanism for regulating $\mathrm{T}$ cell numbers [47]. Those effector CD8 T cells that escape PCD differentiate into memory $\mathrm{T}$ lymphocytes (MTL), which provide long-term adaptive immunity through robust recall responses [48-50]. For long-term persistence, and self-renewal, MTL must also undergo a steady rate of homeostatic proliferation (HSP), which preferentially occurs in the bone marrow [51-53]. The homeostatic proliferation of MTL is critically dependant on survival cytokines such as IL-15, which induce the expression of antiapoptotic molecules such as Bcl-2, Bcl- $\mathrm{X}_{\mathrm{L}}$, and Mcl-1 in MTL [54, $55]$.

\section{Cytotoxic Lymphocytes}

PCD not only plays a key role in the development and homeostasis of lymphocytes, but also is used by cytotoxic lymphocytes to kill infected or transformed cells. Contact-dependent, lymphocyte-mediated cytotoxicity proceeds through two pathways. The first involves the action of proteins present in $\mathrm{CD}^{+}$cytotoxic $\mathrm{T}$ cell (CTL) and natural killer $(\mathrm{NK})$ cell granules $[56,57]$. In this pathway perforin $[57,58]$ is required for the entry of serine protease granzymes, which trigger rapid apoptosis in target cells [59]. The second pathway of contact-dependent, lymphocyte killing is triggered by members of TNF-R family of which Fas is the most important [60]. Granzymes A and B are the most abundant granzymes in mice and humans and are the best characterized [44]. When an activated CTL recognizes pMHC, a tight junction is formed between the effector and target, into which the contents of lytic granules are secreted [61]. The synapse formed between a CTL and a target cell is relatively short lived (minutes), and very few granules need to be released to destroy a target cell $[62,63]$. Granzyme B is released into the synapse and is endocytosed into a target cell through a mechanism that is still not clear. Perforin delivers granzymes into the cytoplasm of target cells by releasing it from endocytic compartments (Figure 3) [64]. Once released into the cytoplasm, GrB rapidly traffics to the nucleus [65] and initiates death by cleaving protein substrates that either directly or indirectly leads to DNA fragmentation and cell death. Although GrB is a serine protease, like the caspases, its preference is to cleave after aspartic acid in the P1 position [66]. Many studies have shown that a number of procaspases (including caspases $2,3,7,8,9$, and 10) are the substrates of GrB both in vitro and in vivo [44].

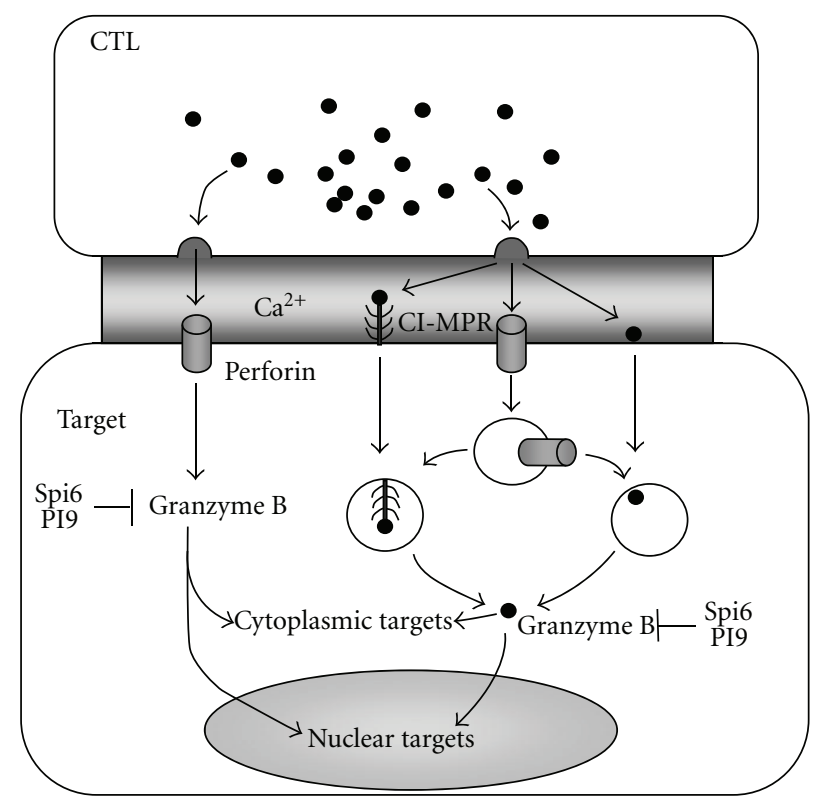

FIGURE 3: The granule pathway of CTL killing. The CTL is shown on top and the target cell on the bottom. Perforin and granzymes are stored in polarized lytic granules and are released into the space between cells. On the left is the earliest model which states that perforin forms pores in the plasma membrane of target cells. In this model, perforin secreted by the effector cell polymerizes in the presence of calcium and forms a channel through which granzymes pass into the target cell. On the right side are two more recent models in which perforin enters the target cell membrane and enters the cell through repair-mediated endocytosis. GrB is thought to enter the cell by binding to the cation-independent mannose-6-P receptor (CI-MPR) followed by receptor internalization or through some other uptake mechanism independent of CI-MPR. In both models granzyme is released into an endolysosomal compartment where it is rendered harmless. Internalized perforin provides a signal for GrB to leave the compartment. GrB released into the cell cleaves cytoplasmic and nuclear substrates leading to apoptosis.

\section{Self-Inflicted Damage of T Lymphocytes}

Given the effectiveness of the granule exocytosis pathway of death, it is not surprising that CTL and NK cells are susceptible to self-inflicted damage. A dramatic demonstration of this is the phenotype of perforin-deficient CTL. Perforindeficient mice harbor CTL which are defective in granulemediated killing [60] but also undergo less PCD in vitro [67]. Furthermore, pharmacological inhibition of perforin decreases CTL PCD [68]. When perforin-deficient mice were challenged in vivo with allografts [69] viruses, or intracellular bacteria [70-73], a massive expansion in the number of CTL compared to wild-type controls was observed. It has been suggested that perforin and the granule-pathway of apoptosis play an important role in eliminating CTLs after infection. [74]. Support for the generality of this mechanism comes from the report of elevated numbers of CTL in patients with familial hemophagocytic lymphohistiocytosis (FHL) who harbor homozygous loss-of-function defects in the perforin gene [75]. 
There is evidence to indicate that granzymes are turned against CTLs through both fratricide and suicide. The traffic of granzymes into a target cell is achieved by the unidirectional exocytosis of lytic granules into the secretory synapse [61]. Therefore, the simplest explanation for CTL self-destruction is that CTLs become the targets for killing by other CTL fratricide which may be relevant for downregulating CD8 $\mathrm{T}$ cell immune responses if CTLs express pMHC [76], which may happen if CD8 T cells are the target of virus infection, such as in individuals infected with Human T lymphotropic virus [77]. Of potentially wider relevance are observations that, in the course of delivering the lethal hit, a CTL internalizes then reexpresses pMHC, on its plasma membrane rendering it a target for fratricidal killing [78]. However, fratricide caused by the reexpression of target cells pMHC remains an in vitro phenomenon observed with some $[78]$ but not all $[68,79]$ cultured CTL lines.

Although the delivery of granzymes to target cells is highly ordered there is evidence to suggest that granzymes become "misdirected" into the cytoplasm of a CTL. During the killing of a target, the perforin/granzyme pathway also induces the death of the CTL itself delivering the lethal hit in a fratricide-independent manner (suicide) [68]. Several reports indicate the presence of $\mathrm{GrB}$ in compartments other than that of lytic granules or the cytoplasm of a target cell. During CTL killing, up to one-third of the granzyme A and $B$ produced is secreted directly via the constitutive secretory pathway rather than from lytic granules [80]. This source of granzymes is thought to be responsible for bystander killing of targets, which occurs without the formation of conjugates with CTL. It has long been appreciated that granzymes A and $\mathrm{B}$ can be found in the serum during CTL immune reactions, indicating a potential extracellular source of misdirected killing molecules [21]. PCD induced by GrB- leakage has been observed in NK cells, which supports the idea of that self-inflicted death may be general to cytotoxic lymphocytes [81].

\section{Protection of Cytotoxic Lymphocytes from Self-Inflicted Damage by Serpins}

Whichever way GrB enters the cytoplasm, what is now clear is that serpins IC play a key role in protecting CTL from self-inflicted damage. PI9 is an endogenous serpin ${ }_{\text {IC }}$ specific for GrB, expressed in human CTL and NK cells [32]. Expression of transgenic PI9 improved the viability of human CTL, suggesting that upregulation of PI9 may protect CTLs from self-inflicted damage [82]. Further evidence comes from the observation that transgenic Spi6 protected mouse CTL from GrB and increased the number of antigenspecific CD8 T cells after infection of mice with Lymphocytic Choriomeningitis virus (LCMV) [83]. However, the most convincing evidence that GrB-specific serpins IC $_{\text {c }}$ protect CTLs from self-inflicted damage comes from the study of Spi6 KO mice. The study of CTL from Spi6 KO revealed that Spi6 inhibits $\mathrm{GrB}$ in the cytoplasm after it leaks the cytotoxic granules by acting as a classic suicide substrate (Figure 1) [84]. The increase in cytoplasmic GrB activity leads to the induction of PCD and decreased clonal burst of CTL specific for LCMV and Listeria monocytogenes [84, 85]. Importantly, the impaired viability of Spi6 KO CTL results in compromised immunity to intracellular pathogens [84]. The Spi6 gene is a transcriptional target of the $I d 2$ transcription factor and $I d 2 \mathrm{KO}$ mice have a similar impaired CTL clonal burst as Spi6 KO mice [86]. Spi6 not only protected CTL from PCD caused by cytoplasmic GrB, but also ensured the integrity of cytotoxic granules by preventing granzymemediated breakdown [84] (Figure 4). Spi6 KO CTLs either have a reduced number of granules in their cytotoxic vesicles, or have malformed cytotoxic vesicles. This defect could be corrected by GrB deficiency, suggesting an active role for $\mathrm{GrB}$ in granule breakdown. How cytoplasmic GrB feeds back and causes the destruction of cytotoxic granules is not known, but presumably granule structural proteins could be directly attacked by $\mathrm{GrB}$ or by downstream products of $\mathrm{GrB}$ activity.

Invariant NKT (iNKT) cells are a subset of T lymphocytes that express an invariant TCR ( $\mathrm{V} \alpha 14)$ and the NK cell surface marker NK1.1 [87]. Recognition of glycolipid antigens presented in context of the CD1d MHC molecule leads to the activation of iNKT cells and the rapid production of both IFN- $\gamma$ (Th1) and IL-4 (Th2) cytokines, which govern a wide variety of immune reactions [88]. In addition to an immunomodulatory role, iNKT cells also kill cancer cells using the perforin/GrB pathway of contact-dependent, lymphocyte-mediated cytotoxicity [44, 88]. Spi6-deficient iNKT cells harbored increased levels of GrB and were susceptible to PCD after stimulation with the PBS-57 glycolipid antigen $[88,89]$. The increased activation-induced apoptosis resulted in impaired survival and a decreased clonal burst size of Spi6 KO iNKT cells after challenge in vivo. Therefore, inhibition of GrB by Spi6 protects of cytotoxic lymphocytes of the innate as well as the adaptive branches from selfinflicted damage.

\section{Serpins and the Development and Persistence of Memory T Cells}

Immunological memory is unique to vertebrates and is defined as the persistence of a reactive state initiated by antigen challenge. This persistence of an immunological reactive state is dependant on memory lymphocytes, which increase the frequency of pathogen-specific cells and are functionally superior to naïve lymphocytes. Studies from our laboratory and others support a linear differentiation model of MTL development [48-50, 90, 91]. A prediction of this model is that MTLs are the direct progeny of CTL [50], Th1 [49], or Th2 [48] effectors. Since effector T cells are highly susceptible to PCD, the differentiation of memory cells requires the escape of effectors from PCD, which may be facilitated by stochastic changes in a small proportion of memory cell precursors. This may involve the upregulation of so-called protective genes that encode antiapoptotic factors in memory cell precursors. Work from our group has shown that two different serpins IC $_{\text {expressed }}$ in CTL control the MTL in different ways. 


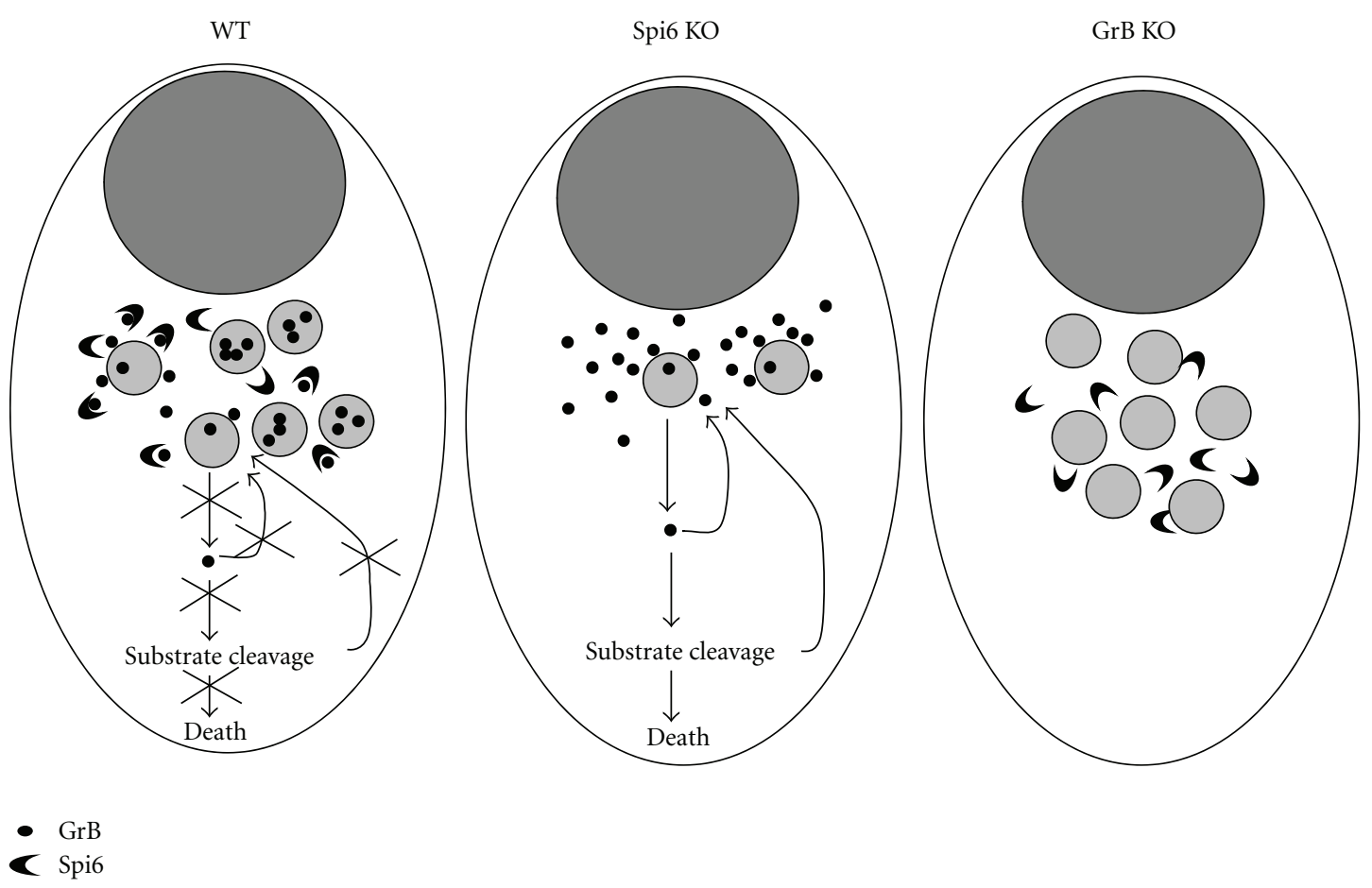

FIGURE 4: Spi6 protects CTL from self-inflicted damage. Spi6 inhibits GrB-mediated apoptosis of CTLs. Spi6 inhibits GrB in the cytoplasm of wild-type (WT) CTLs (nucleus in dark gray), through the formation of an irreversible complex. The inhibition of GrB (crossed line) blocks the cleavage and activation of target enzymes and the induction of death (crossed line). The breakdown of granules integrity and the release of more GrB, either directly by cytoplasmic GrB or downstream targets, is thus inhibited by Spi6. Cytoplasmic GrB is not blocked in Spi6 KO CTLs and so there is increased death. A positive feedback loop whereby GrB releases into the cytoplasm catalyzes further leakage from granules then ensues because GrB causes granule damage. There is no GrB-mediated breakdown of granules in GrB KO CTLs resulting in increased granule number and decreased death.

8.1. Serine Protease Inhibitor 2A (Spi2A). Spi2A (Seprina3g)

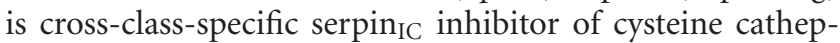
sins which protects cells from the lysosomal pathway of PCD [7], which is upregulated in the MTL and their precursors [92]. Overexpressing Spi2A increased the number of MTL [92]. Conversely, expression of antisense Spi2A mRNA blocked the development of MTL after infection with LCMV [92]. However, the Serpina3g locus contains several genes, which share a very high degree of homology to Spi2A, and so it is difficult to definitely ascribe the effects on memory cell development uniquely to Spi2A [93]. To examine the role of Spi2A in MTL self-renewal and HSP, we generated Spi2A knockout (Spi2A KO) mice. There was an age-dependent deficit and impaired self-renewal of MTL in Spi2A KO mice [94]. Spi2A transcription was induced by IL-15 and other survival cytokines. The defective HSP of both endogenous and LCMV-specific MTL in Spi2A KO mice could be corrected by cathepsin B deficiency. Thus, demonstrating that inhibition of cathepsin B was the physiological target of Spi2A in maintaining MTL. Therefore, the protection from cathepsin B-mediated PCD by Spi2A is a mechanism by which the survival cytokine IL-15 ensures MTL self-renewal through HSP (Figure 5).

8.2. Serine Protease Inhibitor 6 (Spi6). The work with Spi6 $\mathrm{KO}$ mice has clearly demonstrated a role for an endogenous
GrB inhibitor in protecting CTL from self-inflicted damage and controlling the clonal burst of pathogen-specific CTL [84]. However, despite an $80-90 \%$ reduction in the size of the CTL pool the size of the MTL pool, was the same as wild-type in Spi6 KO mice [85]. Therefore the development of MTL was independent of Spi6 (Figure 5). Although Spi6 was required for the survival of the majority of CTL it was dispensable for the survival of the small proportion of the CTL pool that were memory cell precursors. The likely reason for this was that memory cell precursors (indicated by the expression of the interleukin-7R-IL-7R) express low levels of GrB and so are not susceptible to GrB-mediated self-destruction (Figure 6). However, in Spi6 KO mice the size of secondary CTL clonal burst was almost completely abolished in recall responses after reinfection with high doses of pathogenic LCMV [85]. Therefore, although Spi6 is not required for the development of primary MTL it still controls memory cell responses by determining the size of the CTL clonal burst in after reinfection. The T-bet transcription factor is required for the differentiation of CTL but not long-term memory CD8 T cells [95]. GrB is a transcriptional target of T-bet and so the dichotomy between short-lived $\mathrm{GrB}^{\text {hi }} \mathrm{CTL}$ and $\mathrm{GrB}^{\mathrm{lo}}$ memory cell precursors can be explained in terms of graded expression of T-bet [95]. An attractive hypothesis would be that the coordinate expression of Spi6 and GrB is part of the T-bet transcriptional program that ensures the survival of CTL. 


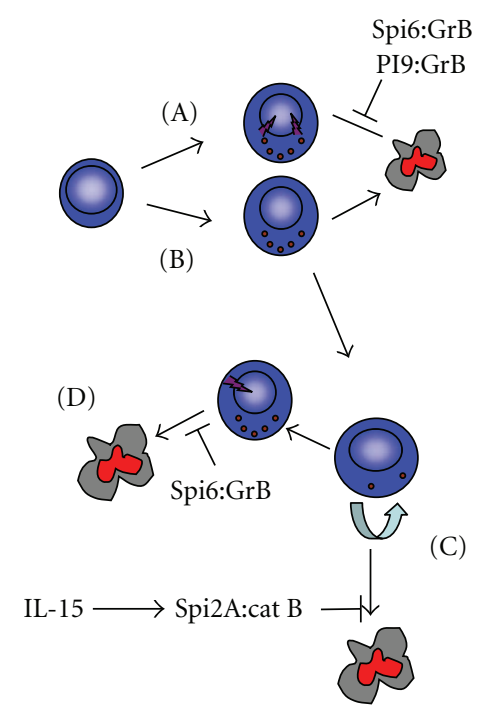

Figure 5: Serpins in memory T-cell development. Stimulation of a naïve CD8 $\mathrm{T}$ cell with pMHC and costimulation results in proliferation and differentiation into (A) a fully differentiated CTL, which is susceptible to self-administered lethal hits (lightening bolt) by GrB. Inhibition of GrB by Spi6 in mice or PI9 in humans protects CTL from PCD. Naïve CD8 T cells also differentiate into memorycell precursors that are characterized by lower levels of $\mathrm{GrB}$ and Spi6. (B). MTL-precursors escape PCD facilitating the development of MTL independent of GrB and Spi6 (C). Expression of Spi2A in MTL is triggered by the IL-15 survival cytokine and required homeostatic proliferative self-renewal through the suppression of cathepsin-mediated PCD. (D) Upon reexposure to pMHC MTL give rise to expansion into secondary CTL, the survival of which requires protection by Spi6 from GrB-mediated PCD.

The study of Spi2A KO and Spi6 KO mice suggests that serpins IC $_{\mathrm{C}}$ have evolved separate functions in determining the size of a primary CTL (Spi6 inhibition of GrB) versus controlling long-term self-renewal (Spi2A inhibition of cathepsin B). Therefore, it would appear that the lysosomal pathway of PCD regulates the overall level of MTL in response to external cytokine signals whereas GrB regulates the level of short-term CTL.

\section{Protection of Dendritic Cells from CTL}

Dendritic cells (DCs) are the physiological antigenpresenting cells that stimulate both naïve CD8 T cells and memory CD8 $\mathrm{T}$ cells to differentiate and proliferate into CTL $[96,97]$. In mice, the CD11 $\mathrm{c}^{++} \mathrm{CD} 8 \alpha^{++} \mathrm{CD} 205^{+} \mathrm{DC}$ population $(\mathrm{CD} 8 \alpha \mathrm{DC})$ can best acquire a wide variety of cellular antigens (including viral proteins) from infected and apoptotic cells and present them on self-class I MHC to cognate $\mathrm{CD} 8 \mathrm{~T}$ cells in a process known as cross-presentation $[98,99]$. CD $8 \alpha$ DCs are also the subset specifically responsible for cross-presentation of LCMV antigens to CD8 T cells [98]. Given the effectiveness of the granule exocytosis pathway to deliver a kiss of death it is not surprising that antigenpresenting DCs are killed by cognate CTL. Experiments with

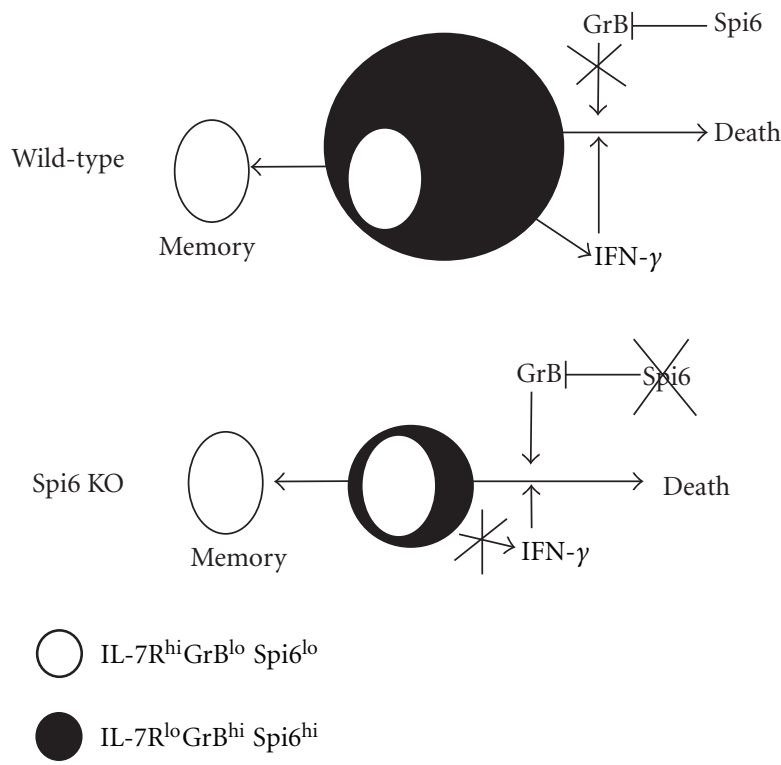

FIGURE 6: Differential effect of Spi6 on CTL and MTL survival. Spi6 is required for the clonal burst but not the development of memory cells. In wild-type CTLs Spi6 suppresses the activity of GrB in the cytoplasm and prevents the death of CTLs thus maintaining the size of the CD8 $\mathrm{T}$ cell clonal burst (outer circle). IFN- $\gamma$ produced by the CD8 $\mathrm{T}$ cell clonal burst causes death and cell loss during the contraction phase. GrB induces the death of CTLs in Spi6 KO mice reducing the size of the clonal burst but also the production of IFN- $\gamma$. This results in negligible cell loss in the contraction phase. Within the clonal burst is a subpopulation of IL-7R ${ }^{\text {hi }}$ memory cells precursors that have low expression of GrB and Spi6 and so their survival is unaffected in Spi6 KO mice. Therefore, the size of the memory-precursor and primary memory pool in Spi6 KO is the same as wild-type mice.

perforin-deficient CTL show that primary CTLs eliminate DC that express cognate peptide-antigen/MHC (pMHC) as part of a negative-feedback mechanism that limits the expansion of the immune response to tumor [100] or virus [101]. A negative regulatory loop working through the killing of DC has also been reported for the priming of MTL responses $[102,103]$. However, the fact that DCs are still highly effective at priming CTL expansion implies that they have mechanisms that protect them from the kiss of death.

The upregulation of Spi6 in DC upon maturation or through transgene expression results in the protection of DC from granule-mediated programmed cell death (PCD) in vitro [104]. Using Spi6 KO mice we have shown that Spi6 protects DC from the kiss of death by inhibiting GrB delivered by CTL [105]. Infection of Spi6 KO mice with LCMV revealed impaired survival of CD $8 \alpha$ DC. The impaired survival of Spi6 KO CD $8 \alpha$ DC resulted in impaired priming and expansion of both primary and memory LCMV-specific CTLs, which could be corrected by GrB deficiency. The rescue in the clonal burst obtained by GrB elimination demonstrated that GrB was the physiological target through which Spi6 protected DC from CTL. Therefore, the negative regulation of DC priming of CD8 T lymphocyte immunity 


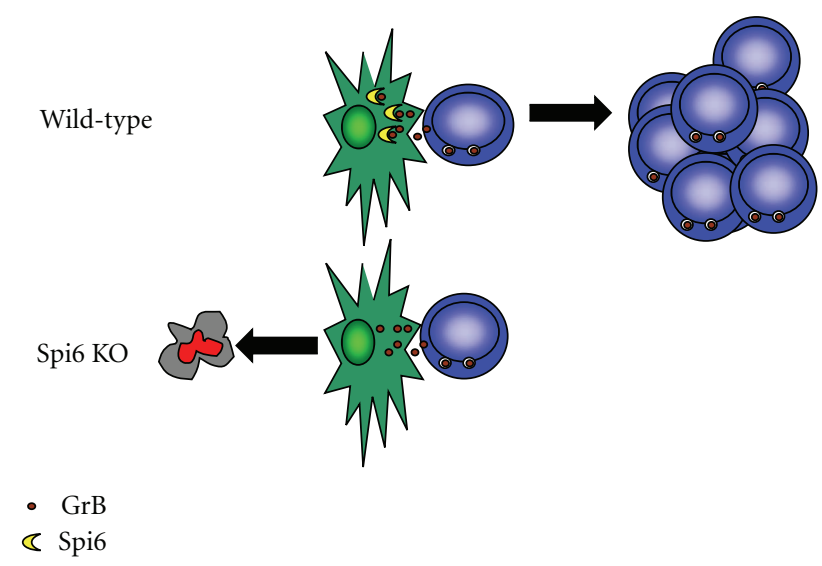

Figure 7: Spi6 protects of CD $8 \alpha$ DC from the kiss of death from $\mathrm{GrB}$. In wild-type mice presentation of $\mathrm{pMHC}$ and costimulation by CD $8 \alpha$ DC stimulate the expansion of cognate CTL. Cognate CD $8 \alpha$ DCs are protected from killing by CTL GrB through inhibition by Spi6. In Spi6 KO mice, GrB is not inhibited and so the killing of CD $8 \alpha$ DC impairs the expansion of CTL. This model is for both the recognition of CD $8 \alpha$ DC by primary CTL and secondary (memory) CTL.

by CTL killing is mitigated by the physiological inhibition of GrB by Spi6 (Figure 7).

\section{Serpins and CTL-Driven Inflammatory Diseases}

Granzymes have been implicated as tissue-damaging agents in a variety of inflammatory and autoimmune diseases, including Graft versus Host Disease (GvHD) [106, 107], rheumatoid arthritis $[108,109]$, atherosclerosis $[110,111]$, Crohn's diseases [112], Rasmussen's encephalitis [113], and Systemic Lupus Erythematosus [114]. Expression studies have located PI9 to nonlymphoid cells in immunoprivileged sites and at the sites of inflammatory reactions $[82,115,116]$. Therefore, it has been suggested that GrB-specific serpin IC, such as PI9 and Spi6, in addition to protecting DCs, may also have a more general protective role for bystander cells in CTL-mediated inflammation. Given the wide variety of inflammatory diseases caused by CTLs, it is likely that the upregulation of PI9 or equivalent serpin IC $_{\text {in nonlymphoid }}$ tissue may be a common strategy for limiting pathological tissue damage. In addition, PI9 may also protect from inflammatory disease by inhibiting proteases other than GrB. Interleukin 1 (IL-1) beta converting enzyme (ICE; caspase 1 ) is required for the production of proinflammatory IL1 and IL-18 cytokines. PI9 not only inhibits GrB as a classical suicide substrate, but can also inhibit caspase 1 through a similar mechanism [3]. This interaction seems to be physiologically relevant in vascular smooth muscle cells where PI9 regulates the production of IL- $1 \beta$ and IL-18 through inhibition of caspase 1 [117]. A potential protective role for PI9 in inflammatory atherosclerosis is suggested by the lower expression in human atherosclerotic lesions [117] (Figure 5).

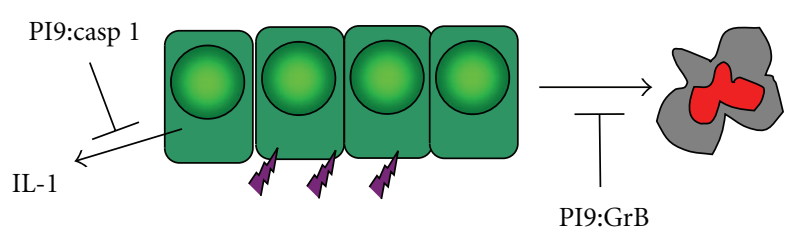

Figure 8: Protection of bystander cells from damage by $\mathrm{T}$ lymphocytes. PI9 inhibits the PCD of bystander cells induced by GrB after the delivery of a lethal hit (lightening bolt) by CTL. PI9 controls the secretion of proinflammatory IL-1 by inhibiting caspase 1 in endothelial cells.

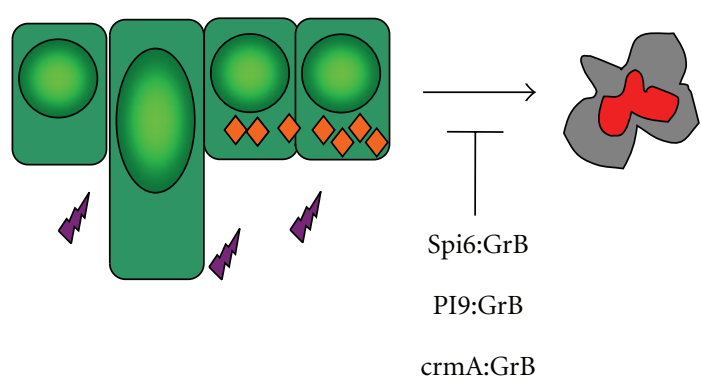

FIGURE 9: Serpins and immunoevasion. Cells infected with poxvirus (diamond) produce crmA, which inhibits GrB-mediated PCD delivered as a lethal hit (lightening bolt) by CTL. Spi6 and PI9 when upregulating in tumor cells (enlarged cell) can protect from GrB delivered by CTLs.

\section{Serpins and Immunoevasion}

Serpins ${ }_{I C}$ play a critical role in $\mathrm{T}$ lymphocyte mediated immunity. However, intracellular pathogens may use serpins $_{\text {IC }}$ to inhibit the same proteases cell in order to escape $\mathrm{T}$ cell immunity. Viruses exploit the ability of seprins IC to suppress GrB activity in order to escape destruction by CTLs. Several different viruses have developed different mechanisms to suppress GrB. Poxvirus-encoded CrmA can inhibit GrB in vitro using a classic serpin mechanism [118] (Figure 8). In addition, CrmA can also inhibit several caspases [6] and so overexpression can inhibit both Fasand GrB-mediated killing $[5,119]$. Therefore, CrmA allows cowpox virus-infected cells to potentially escape both the granule-mediated and the Fas-FasL-mediated pathways of CTL killing [44]. This mechanism of immunoevasion is in contrast to the inhibition of GrB by the adenovirus assembly protein L4-100K, which acts as competitive inhibitor of granzyme cleavage of pro-apoptotic substrates. Inhibition of GrB by L4-100K is effective through this mechanism because it is produced in vast excess to GrB in adenovirus-infected cells.

It has been suggested that inhibition of GrB by serpins IC may represent a novel escape mechanism by which tumors may evade CTL-mediated immunosurveillance (Figure 9). This claim is based on the observation that over-expression of Spi6 and PI9 protects tumor cell lines from CTL-mediated lysis and that PI9 is expressed in both Hodgkin's ( $\mathrm{T}$ and $\mathrm{B}$ cell) and non-Hodgkin's lymphomas and also breast, 


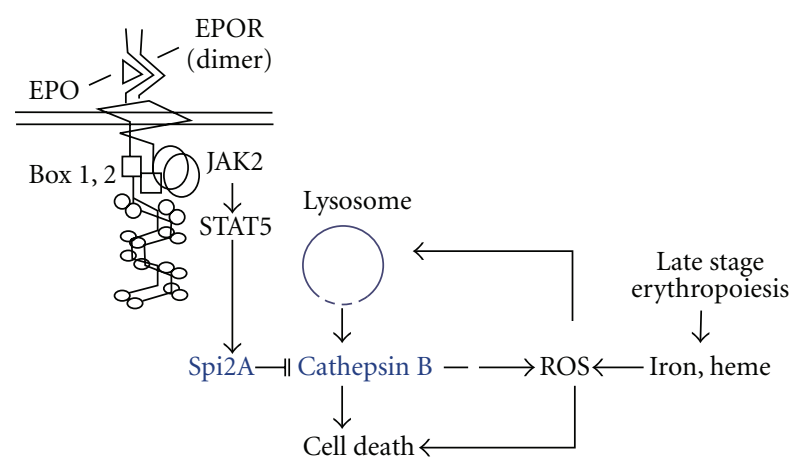

FIgure 10: Spi2A is an EPO-specific protective factor. A model is depicted in which EPO promotes erythroblast formation through the expression of Spi2A, which inhibits cathepsin B after it is released from lysosomes within stressed or compromised erythroblasts. Suppression of cathepsin B by Spi2A inhibits PCD and further production of ROS and LMP.

colon, and cervix carcinomas $[104,120]$. However, PI9 is widely expressed in normal leukocytes and normal epithelial cells [82], and it is still yet to be determined whether the level of expression in cancer cells is any higher than the level in noncancerous control tissue [120]. Despite this, the correlation of between PI9 expression and the poor prognosis of patients with anaplastic large cell lymphoma suggests that the escape of tumors from CTL-mediated immunosurveillance may involve protection from GrB [121].

\section{Serpins in Blood Cell Development}

In response to anemia, Erythropoietin (EPO) is produced by renal interstitial fibroblasts [122] then acts within bone marrow to promote erythroid progenitor expansion via its JAK2 kinase-coupled cell surface receptor (EPOR) [123, 124]. Global gene expression profiling of erythroblasts revealed the mouse serpin Spi2A (Serpina3g) to be a major EPO/EPOR target, our own unpublished findings. The work with Spi2A $\mathrm{KO}$ mice showed that following hemolysis, irradiation, or marrow transplantation, Spi2A-deficiency sharply worsened anemia and also compromised EPO-induced erythropoiesis. This involved Spi2A cytoprotection of maturing erythroblasts. In vivo, compound disruption of Spi2A plus lysosomal cathepsin $\mathrm{B}$ restored EPO-responsiveness and protected from anemia. Pharmacological inhibition of cathepsins $\mathrm{B} / \mathrm{L}$ also enhanced EPO-induced red cell formation in normal mice, and in an EPO-dependent human EPC model. Therefore, Spi2A (as induced upon EPOR/JAK2 ligation) plays an integral role in EPO- and anemia-dependent erythropoiesis. We propose that Spi2A inhibits cathepsin B and/or L when released from lysosomes in erythroblasts after damage by ROS $[125,126]$. ROSs are generated by iron and heme accumulation in erythroblasts [127] (Figure 10).

Spi2A is also upregulated in long-term hematopoietic stem cells (LT-HSC) [128]. However, what aspects of LT-HSC biology Spi2A controls remain to be determined.

\section{Therapeutic Potential of T-Cell Serpins}

13.1. Vaccines and Immunotherapy. A challenge for the future is to translate our knowledge of $\mathrm{T}$ lymphocyte biology into new ways of harnessing cellular immunity to combat infection, cancer, and inflammatory disease. Recent insights into how serpins IC control the development and function of both effector and memory $\mathrm{T}$ lymphocytes may provide new translational opportunities.

The human serpin IC PI9 and its mouse homologue Spi6 can influence CD8 T-cell responses by both affecting the viability of DC antigen-presentation cells $[105,129]$ and CTL [82-84] through the inhibition of cytoplasmic GrB. In terms of cost and safety, DNA vaccination is an attractive alternative to live vaccination, but overall is not as effective in generating long-lived protective CTL [130]. Therefore, there is a need for effective adjuvants to make DNA vaccines more useful against viruses and tumors [131]. One potential adjuvant strategy is to improve the efficiency of DC priming by increasing viability. In this regard, DNA encoding PI9 or Spi6 could boost secondary memory responses by protecting DC from CTL killing [131, 132]. A preliminary DNA vaccination studies against tumors in mice have indicated the feasibility of using Spi6 DNA as an adjuvant in this way [133].

13.2. Transplantation and Autoimmunity. Clinical trials utilizing mesenchymal stem cells (MSC) in tissue engineering and as immunosuppressive agents have been initiated worldwide. We have demonstrated that the expression of Spi6 is required for the protection of transplanted MSC from allospecific CTL and subsequent survival and immunosuppressive activity [134]. Expression of transgenic PI9 protected both mouse [134] and human MSC [135] from CTL killing. Importantly, transgenic PI9 improved the survival and function of MSC after transplantation to allo-specific recipient mice [134]. Therefore, the delivery of PI9 to MSC after allo-transplantation may increase survival and clinical usefulness.

Protein therapy using $\mathrm{T}$ lymphocyte-relevant serpin ${ }_{\mathrm{IC}}$ might also be useful in alleviated inflammatory disease caused by GrB such as GvHD [106], rheumatoid arthritis [108], atherosclerosis [110], Crohn's diseases [112], Rasmussen's encephalitis [113, 136], and Systemic Lupus Erythematosus [114] and allograft rejection [137]. Administration of recombinant Spi6 and PI9 may therefore be useful in alleviating CTL-associated inflammatory diseases by inhibiting extracellular GrB.

13.3. Anemia and Cancer. Clinically, EPO is used to treat the anemia of chronic renal disease [138], and at restricted dosing the anemia of cancer and chemotherapy [139]. However, EPO may also worsen certain cancers (e.g., head/neck and breast carcinomas) via unresolved routes [139]. We have shown in mice that Spi2A facilitates the activity of EPO in anemia by protecting erythroblasts from ROS/cathepsin B/Ldriven PCD, our own unpublished findings. Humans lack an obvious functional homologue of Spi2A that inhibits cysteine cathepsins [93] and no SERPINA gene is upregulated by 
EPO in human erythroblasts, our own unpublished findings. However, pharmacological inhibition of cathepsin B/L can mimic the cytoprotective effects of EPO in mice and in a human erythroblast model, therefore suggesting the presence of human analogue with the properties of Spi2A, our own unpublished findings. Clinically, if small molecule inhibitors to cathepsin-B/L [140] were administered during anemia, such compounds might act in erythroid cell-intrinsic ways to bolster red cell production. This could decrease effective EPO dosing levels, potentially lessen hypertensive side-effects of EPO [141, 142], and might also benefit chemotherapy patients for whom EPO therapy is now limited due to potential effects on cancer progression $[123,139,141]$.

13.4. Biological Pitfalls. The study of Spi6 KO mice has proven to be useful in pointing out potential pitfalls in

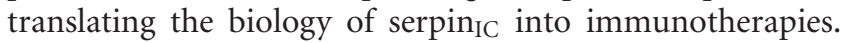
Spi6 KO mice have revealed that improving CTL viability by protecting from self-inflicted damage [84] does not necessarily increase the size of the CD8 memory T-cell pool [85]. This is because the pathways of programmed cell death that control memory cell viability are different from those controlling CTL viability and clonal burst size. Therefore, targets that increase the size of the CTL pool may not necessarily result in an increase in the pool of long-term memory $\mathrm{T}$ cells. So in order to maximize differentiation of long-term memory cells one must suppress the deathpathways specific to memory $\mathrm{T}$ cells. In this regard the suppression of cysteine cathepsins by transgenic Spi2A may be useful as an adjuvant approach. However, there is no direct structural homologue of Spi2A in humans. A possible functional nonserpin homologue of Spi2A in humans is the leukocystatin (cystatin F), which is upfregulated in memory CD8 T cells [143], inhibits cathepsin L in the cytoplasm and nucleus, and is uniquely expressed in leukocytes [144].

Protein therapy for inflammatory diseases with Spi6 or PI9 is likely to be limited to the inhibition of extracellular GrB. This is because of the difficulty of delivering intracellular proteins to the cytoplasm. Since GrB induces apoptosis upon entry to the cytoplasm the inability to deliver $\operatorname{serpin}_{\mathrm{IC}}$ to this cellular compartment may severely limit the effectiveness of PI9-based protein therapy in alleviating inflammatory diseases.

\section{Conclusion}

Our work to date has uncovered several aspects of the biology of serpin $\mathrm{IC}$ that may hold the promise for new therapies that alleviate inflammatory disease or anemia or boost protective T lymphocyte immune responses. Perhaps the main translational value of this work may be realized by developing small molecules that mimic the beneficial activ-

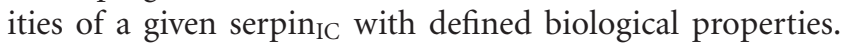
Thus, small molecule inhibitors of the relevant executioner protease targeted by physiologically relevant serpin IC $_{\text {in }} \mathrm{T}$ cells may boost the development of memory $\mathrm{T}$ cells and be useful adjuvants. We have demonstrated the feasibility of this approach for Spi2A. Synthetic inhibitors of cathepsin B
[140] can boost the number LCMV-specific memory CD8 T cells by inhibiting programmed cell death [92]. This finding is consistent with earlier work that showed that synthetic inhibitors of cathepsin B and cathepsin L can protect human activated $\mathrm{T}$ cells from programmed cell death in vitro [26]. However, current cathepsin $\mathrm{B} / \mathrm{L}$ inhibitors have poor cell uptake and high toxicity, which limits effectiveness in vivo. Therefore, there is an unmet need for a clinically useful cathepsin $\mathrm{B} / \mathrm{L}$ to mimic the biological properties of the human analogue of Spi2A. In addition to application to immunotherapy, clinically useful cathepsin B/L inhibitors may also be used to treat the anemia of chronic disease and provide a new means to lessen EPO dosing and so in turn, untoward effects of EPO on hypertension, and/or cancer progression, our own unpublished findings.

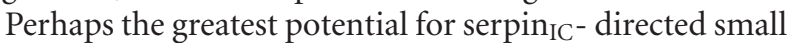
molecule development lies in the development of clinically useful GrB inhibitors. A tetrapeptide inhibitor of GrB shows good efficacy in vitro but due to poor cellular uptake inhibits CTL-mediated target cell killing 1000-times less effectively and so is unlikely to be effective in vivo [145]. Therefore, the development of GrB inhibitors with improved cellular efficacy may result in clinically useful drugs to alleviate against a wide variety of inflammatory diseases.

\section{Acknowledgments}

The work in the laboratory is supported by the National Institutes of Health Grant AI 40608 and program grants from the Wellcome Trust, the Medical Research Council, and Cancer Research UK awarded to P.G. Ashton-Rickardt. The author thanks his collaborators for generating the data, published and unpublished, that formed the basis of this paper.

\section{References}

[1] G. A. Silverman, P. I. Bird, R. W. Carrell et al., "The serpins are an expanding superfamily of structurally similar but functionally diverse proteins. Evolution, mechanism of inhibition, novel functions, and a revised nomenclature," Journal of Biological Chemistry, vol. 276, no. 36, pp. 3329333296, 2001.

[2] E. Remold-O'Donnell, "The ovalbumin family of serpin proteins," FEBS Letters, vol. 315, no. 2, pp. 105-108, 1993.

[3] R. R. Annand, J. R. Dahlen, C. A. Sprecher et al., "Caspase1 (interleukin-1 $\beta$-converting enzyme) is inhibited by the human serpin analogue proteinase inhibitor 9," Biochemical Journal, vol. 342, no. 3, pp. 655-665, 1999.

[4] T. Komiyama, C. A. Ray, D. J. Pickup et al., "Inhibition of interleukin- $1 \beta$ converting enzyme by the cowpox virus serpin CrmA. An example of cross-class inhibition," Journal of Biological Chemistry, vol. 269, no. 30, pp. 19331-19337, 1994.

[5] M. Tewari and V. M. Dixit, "Fas- and tumor necrosis factorinduced apoptosis is inhibited by the poxvirus crmA gene product," Journal of Biological Chemistry, vol. 270, no. 7, pp. 3255-3260, 1995.

[6] Q. Zhou, S. Snipas, K. Ortht, M. Muzio, V. M. Dixit, and G. S. Salvesen, "Target protease specificity of the viral 
serpin CrmA. Analysis of five cascapses," Journal of Biological Chemistry, vol. 272, no. 12, pp. 7797-7800, 1997.

[7] N. Liu, S. M. Raja, F. Zazzeroni et al., "NF- $\kappa$ B protects from the lysosomal pathway of cell death," EMBO Journal, vol. 22, no. 19, pp. 5313-5322, 2003.

[8] M. Al-Khunaizi, C. J. Luke, Y. S. Askew et al., "The serpin SQN-5 is a dual mechanistic-class inhibitor of serine and cysteine proteinases," Biochemistry, vol. 41, no. 9, pp. 31893199, 2002.

[9] C. Schick, P. A. Pemberton, G. P. Shi et al., "Cross-class inhibition of the cysteine proteinases cathepsins $\mathrm{K}$, L, and $\mathrm{S}$ by the serpin squamous cell carcinoma antigen 1: a kinetic analysis," Biochemistry, vol. 37, no. 15, pp. 5258-5266, 1998.

[10] C. J. Luke, S. C. Pak, Y. S. Askew et al., "An intracellular serpin regulates necrosis by inhibiting the induction and sequelae of lysosomal injury," Cell, vol. 130, no. 6, pp. 1108-1119, 2007.

[11] Q. L. Deveraux, N. Roy, H. R. Stennicke et al., "IAPs block apoptotic events induced by caspase- 8 and cytochrome $\mathrm{c}$ by direct inhibition of distinct caspases," EMBO Journal, vol. 17, no. 8, pp. 2215-2223, 1998.

[12] V. Turk and W. Bode, "The cystatins: protein inhibitors of cysteine proteinases," FEBS Letters, vol. 285, no. 2, pp. 213219, 1991.

[13] M. Leist and M. Jaattela, "Four deaths and a funeral: from caspases to alternative mechanisms," Nature Reviews Molecular Cell Biology, vol. 2, no. 8, pp. 589-598, 2001.

[14] K. F. Ferri and G. Kroemer, "Organelle-specific initiation of cell death pathways," Nature Cell Biology, vol. 3, no. 11, pp. E255-263, 2001.

[15] K. Schulze-Osthoff, A. C. Bakker, B. Vanhaesebroeck, R. Beyaert, W. A. Jacob, and W. Fiers, "Cytotoxic activity of tumor necrosis factor is mediated by early damage of mitochondrial functions. Evidence for the involvement of mitochondrial radical generation," Journal of Biological Chemistry, vol. 267, no. 8, pp. 5317-5323, 1992.

[16] D. Vercammen, R. Beyaert, G. Denecker et al., "Inhibition of caspases increases the sensitivity of L929 cells to necrosis mediated by tumor necrosis factor," Journal of Experimental Medicine, vol. 187, no. 9, pp. 1477-1485, 1998.

[17] D. Vercammen, G. Brouckaert, G. Denecker et al., "Dual signaling of the Fas receptor: initiation of both apoptotic and necrotic cell death pathways," Journal of Experimental Medicine, vol. 188, no. 5, pp. 919-930, 1998.

[18] H. C. Ha and S. H. Snyder, "Poly(ADP-ribose) polymerase is a mediator of necrotic cell death by ATP depletion," Proceedings of the National Academy of Sciences of the United States of America, vol. 96, no. 24, pp. 13978-13982, 1999.

[19] A. M. Tolkovsky, L. Xue, G. C. Fletcher, and V. Borutaite, "Mitochondrial disappearance from cells: a clue to the role of autophagy in programmed cell death and disease?" Biochimie, vol. 84, no. 2-3, pp. 233-240, 2002.

[20] G. Denecker, D. Vercammen, M. Steemans et al., "Death receptor-induced apoptotic and necrotic cell death: differential role of caspases and mitochondria," Cell Death and Differentiation, vol. 8, no. 8, pp. 829-840, 2001.

[21] J. Lieberman, "The ABCs of granule-mediated cytotoxicity: new weapons in the arsenal," Nature Reviews Immunology, vol. 3, no. 5, pp. 361-370, 2003.

[22] M. Jaattela and J. Tschopp, "Caspase-independent cell death in T lymphocytes," Nature Immunology, vol. 4, no. 5, pp. 416423, 2003.

[23] C. E. Chwieralski, T. Welte, and F. Bühling, "Cathepsinregulated apoptosis," Apoptosis, vol. 11, no. 2, pp. 143-149, 2006.
[24] M. E. Guicciardi, J. Deussing, H. Miyoshi et al., "Cathepsin B contributes to TNF- $\alpha$-mediated hepatocyte apoptosis by promoting mitochondrial release of cytochrome c," Journal of Clinical Investigation, vol. 106, no. 9, pp. 1127-1137, 2000.

[25] M. Van Eijk and C. De Groot, "Germinal center B cell apoptosis requires both caspase and cathepsin activity," Journal of Immunology, vol. 163, no. 5, pp. 2478-2482, 1999.

[26] M. C. Michallet, F. Saltel, M. Flacher, J. P. Revillard, and L. Genestier, "Cathepsin-dependent apoptosis triggered by supraoptimal activation of $\mathrm{T}$ lymphocytes: a possible mechanism of high dose tolerance," Journal of Immunology, vol. 172, no. 9, pp. 5405-5414, 2004.

[27] X. M. Yuan, W. Li, H. Dalen et al., "Lysosomal destabilization in p53-induced apoptosis," Proceedings of the National Academy of Sciences of the United States of America, vol. 99, no. 9, pp. 6286-6291, 2002.

[28] K. Roberg and K. Öllinger, "Oxidative stress causes relocation of the lysosomal enzyme cathepsin D with ensuing apoptosis in neonatal rat cardiomyocytes," American Journal of Pathology, vol. 152, no. 5, pp. 1151-1156, 1998.

[29] K. Roberg, K. Kågedal, and K. Öllinger, "Microinjection of cathepsin D induces caspase-dependent apoptosis in fibroblasts," American Journal of Pathology, vol. 161, no. 1, pp. 89-96, 2002.

[30] L. Foghsgaard, D. Wissing, D. Mauch et al., "Cathepsin B acts as a dominant execution protease in tumor cell apoptosis induced by tumor necrosis factor," Journal of Cell Biology, vol. 153, no. 5, pp. 999-1009, 2001.

[31] E. Katz, M. R. Deehan, S. Seatter, C. Lord, R. D. Sturrock, and M. M. Harnett, "B cell receptor-stimulated mitochondrial phospholipase A2 activation and resultant disruption of mitochondrial membrane potential correlate with the induction of apoptosis in WEHI-231 B cells," Journal of Immunology, vol. 166, no. 1, pp. 137-147, 2001.

[32] J. Sun, C. H. Bird, V. Sutton et al., "A cytosolic granzyme B inhibitor related to the viral apoptotic regulator cytokine response modifier A is present in cytotoxic lymphocytes," Journal of Biological Chemistry, vol. 271, no. 44, pp. 2780227809, 1996.

[33] J. Sun, L. Ooms, C. H. Bird, V. R. Sutton, J. A. Trapani, and P. I. Bird, "A new family of 10 murine ovalbumin serpins includes two homologs of proteinase inhibitor 8 and two homologs of the granzyme B inhibitor (proteinase inhibitor 9)," Journal of Biological Chemistry, vol. 272, no. 24, pp. 15434-15441, 1997.

[34] N. Liu, Y. Wang, and P. G. Ashton-Rickardt, "Serine protease inhibitor 2A inhibits caspase-independent cell death," FEBS Letters, vol. 569, no. 1-3, pp. 49-53, 2004.

[35] L. Hampson, I. N. Hampson, C. K. Babichuk et al., "A minimal serpin promoter with high activity in haematopoietic progenitors and activated T cells," Hematology Journal, vol. 2, no. 3, pp. 150-160, 2001.

[36] R. H. Schwartz, "Acquisition of immunologic self-tolerance," Cell, vol. 57, no. 7, pp. 1073-1081, 1989.

[37] D. Lo and J. Sprent, "Identity of cells that imprint H-2restricted T-cell specificity in the thymus," Nature, vol. 319, no. 6055 , pp. 672-675, 1986.

[38] P. Kisielow, H. S. Teh, H. Bluthmann, and H. Von Boehmer, "Positive selection of antigen-specific T cells in thymus by restricting MHC molecules," Nature, vol. 335, no. 6192, pp. 730-733, 1988.

[39] B. Scott, H. Bluthmann, H. S. Teh, and H. Von Boehmer, "The generation of mature $\mathrm{T}$ cells requires interaction of the 
$\alpha \beta$ T-cell receptor with major histocompatibility antigens," Nature, vol. 338, no. 6216, pp. 591-593, 1989.

[40] H. S. Teh, P. Kisielow, B. Scott et al., "Thymic major histocompatibility complex antigens and the $\alpha \beta$ T-cell receptor determine the CD4/CD8 phenotype of T cells," Nature, vol. 335, no. 6187, pp. 229-233, 1988.

[41] J. Zerrahn, W. Held, and D. H. Raulet, "The MHC reactivity of the $\mathrm{T}$ cell repertoire prior to positive and negative selection," Cell, vol. 88, no. 5, pp. 627-636, 1997.

[42] P. G. Ashton-Rickardt, "A license to remember," Nature Immunology, vol. 5, no. 11, pp. 1097-1098, 2004.

[43] H. Dooms and A. K. Abbas, "Control of CD4+ T-cell memory by cytokines and costimulators," Immunological Reviews, vol. 211, pp. 23-38, 2006.

[44] J. H. Russell and T. J. Ley, "Lymphocyte-mediated cytotoxicity," Annual Review of Immunology, vol. 20, pp. 323-370, 2002.

[45] L. L. Lau, B. D. Jamieson, T. Somasundaram, and R. Ahmed, "Cytotoxic T-cell memory without antigen," Nature, vol. 369, no. 6482, pp. 648-652, 1994.

[46] K. Murali-Krishna, J. D. Altman, M. Suresh et al., "Counting antigen-specific CD8 T cells: a reevaluation of bystander activation during viral infection," Immunity, vol. 8, no. 2, pp. 177-187, 1998.

[47] R. Ahmed and D. Gray, "Immunological memory and protective immunity: understanding their relation," Science, vol. 272 , no. 5258 , pp. 54-60, 1996.

[48] H. Hu, G. Huston, D. Duso, N. Lepak, E. Roman, and S. L. Swain, "CD4+ T cell effectors can become memory cells with high efficiency and without further division," Nature Immunology, vol. 2, no. 8, pp. 705-710, 2001.

[49] M. Löhning, A. N. Hegazy, D. D. Pinschewer et al., "Longlived virus-reactive memory $\mathrm{T}$ cells generated from purified cytokine-secreting T helper type 1 and type 2 effectors," Journal of Experimental Medicine, vol. 205, no. 1, pp. 53-61, 2008.

[50] J. T. Opferman, B. T. Ober, and P. G. Ashton-Rickardt, "Linear differentiation of cytotoxic effectors into memory T lymphocytes," Science, vol. 283, no. 5408, pp. 1745-1748, 1999.

[51] T. C. Becker, S. M. Coley, E. J. Wherry, and R. Ahmed, "Bone marrow is a preferred site for homeostatic proliferation of memory CD8 T cells," Journal of Immunology, vol. 174, no. 3, pp. 1269-1273, 2005.

[52] G. Cassese, E. Parretta, L. Pisapia, A. Santoni, J. Guardiola, and F. Di Rosa, "Bone marrow CD8 cells down-modulate membrane IL-7R $\alpha$ expression and exhibit increased STAT-5 and p38 MAPK phosphorylation in the organ environment," Blood, vol. 110, no. 6, pp. 1960-1969, 2007.

[53] I. B. Mazo, M. Honczarenko, H. Leung et al., "Bone marrow is a major reservoir and site of recruitment for central memory CD8+ T cells," Immunity, vol. 22, no. 2, pp. 259270, 2005.

[54] D. Hildeman, T. Jorgensen, J. Kappler, and P. Marrack, "Apoptosis and the homeostatic control of immune responses," Current Opinion in Immunology, vol. 19, no. 5, pp. 516-521, 2007.

[55] J. T. Opferman, A. Letai, C. Beard, M. D. Sorcinelli, C. C. Ong, and S. J. Korsmeyer, "Development and maintenance of $\mathrm{B}$ and T lymphocytes requires antiapoptotic MCL-1," Nature, vol. 426, no. 6967, pp. 671-676, 2003.

[56] P. J. Millard, M. P. Henkart, C. W. Reynolds, and P. A. Henkart, "Purification and properties of cytoplasmic granules from cytotoxic rat LGL tumors," Journal of Immunology, vol. 132, no. 6, pp. 3197-3204, 1984.

[57] E. R. Podack, J. D. E. Young, and Z. A. Cohn, "Isolation and biochemical and functional characterization of perforin 1 from cytolytic T-cell granules," Proceedings of the National Academy of Sciences of the United States of America, vol. 82, no. 24, pp. 8629-8633, 1985.

[58] D. Kagi, B. Ledermann, K. Burki et al., "Cytotoxicity mediated by $\mathrm{T}$ cells and natural killer cells is greatly impaired in perforin-deficient mice," Nature, vol. 369, no. 6475, pp. 31-37, 1994.

[59] L. Shi, C. M. Kam, J. C. Powers, R. Aebersold, and A. H. Greenberg, "Purification of three cytotoxic lymphocyte granule serine proteases that induce apoptosis through distinct substrate and target cell interactions," Journal of Experimental Medicine, vol. 176, no. 6, pp. 1521-1530, 1992.

[60] D. Kagi, F. Vignaux, B. Ledermann et al., "Fas and perforin pathways as major mechanisms of T cell-mediated cytotoxicity," Science, vol. 265, no. 5171, pp. 528-530, 1994.

[61] A. Kupfer, S. J. Singer, and G. Dennert, "On the mechanism of unidirectional killing in mixtures of two cytotoxic $\mathrm{T}$ lymphocytes. Unidirectional polarization of cytoplasmic organelles and the membrane-associated cytoskeleton in the effector cell," Journal of Experimental Medicine, vol. 163, no. 3, pp. 489-498, 1986.

[62] T. A. Lyubchenko, G. A. Wurth, and A. Zweifach, "Role of calcium influx in cytotoxic $\mathrm{T}$ lymphocyte lytic granule exocytosis during target cell killing," Immunity, vol. 15, no. 5, pp. 847-859, 2001.

[63] J. C. Stinchcombe, G. Bossi, S. Booth, and G. M. Griffiths, "The immunological synapse of CTL contains a secretory domain and membrane bridges," Immunity, vol. 15, no. 5, pp. 751-761, 2001.

[64] C. J. Froelich, K. Orth, J. Turbov et al., "New paradigm for lymphocyte granule-mediated cytotoxicity: target cells bind and internalize granzyme B, but an endosomolytic agent is necessary for cytosolic delivery and subsequent apoptosis," Journal of Biological Chemistry, vol. 271, no. 46, pp. 2907329079, 1996.

[65] J. A. Trapani, K. A. Browne, M. J. Smyth, and D. A. Jans, "Localization of granzyme B in the nucleus: a putative role in the mechanism of cytotoxic lymphocyte-mediated apoptosis," Journal of Biological Chemistry, vol. 271, no. 8, pp. 4127-4133, 1996.

[66] S. Odake, C. M. Kam, L. Narasimhan et al., "Human and murine cytotoxic $\mathrm{T}$ lymphocyte serine proteases: subsite mapping with peptide thioester substrates and inhibition of enzyme activity and cytolysis by isocoumarins," Biochemistry, vol. 30, no. 8, pp. 2217-2227, 1991.

[67] D. Spaner, K. Raju, L. Radvanyi, Y. Lin, and R. G. Miller, "A role for perforin in activation-induced cell death," Journal of Immunology, vol. 160, no. 6, pp. 2655-2664, 1998.

[68] J. T. Opferman, B. T. Ober, R. Narayanan, and P. G. AshtonRickardt, "Suicide induced by cytolytic activity controls the differentiation of memory CD8+ T lymphocytes," International Immunology, vol. 13, no. 4, pp. 411-419, 2001.

[69] D. Spaner, K. Raju, B. Rabinovich, and R. G. Miller, "A role for perforin in activation-induced $\mathrm{T}$ cell death in vivo: increased expansion of allogeneic perforin-deficient $\mathrm{T}$ cells in SCID mice," Journal of Immunology, vol. 162, no. 2, pp. 1192-1199, 1999.

[70] D. Kagi, B. Odermatt, and T. W. Mak, "Homeostatic regulation of CD8+ T cells by perforin," European Journal of Immunology, vol. 29, no. 10, pp. 3262-3272, 1999. 
[71] M. Matloubian, M. Suresh, A. Glass et al., "A role for perforin in downregulating T-cell responses during chronic viral infection," Journal of Virology, vol. 73, no. 3, pp. 25272536, 1999.

[72] V. P. Badovinac, A. R. Tvinnereim, and J. T. Harty, "Regulation of antigen-specific CD8+ T cell homeostasis by perforin and interferon- $\gamma$," Science, vol. 290, no. 5495, pp. 1354-1357, 2000.

[73] V. P. Badovinac, S. E. Hamilton, and J. T. Harty, "Viral infection results in massive CD8+ $\mathrm{T}$ cell expansion and mortality in vaccinated perforin-deficient mice," Immunity, vol. 18, no. 4, pp. 463-474, 2003.

[74] S. E. Stepp, P. A. Mathew, M. Bennett, G. De Saint Basile, and V. Kumar, "Perforin: more than just an effector molecule," Immunology Today, vol. 21, no. 6, pp. 254-256, 2000.

[75] S. E. Stepp, R. Dufourcq-Lagelouse, F. Le Deist et al., "Perforin gene defects in familial hemophagocytic lymphohistiocytosis," Science, vol. 286, no. 5446, pp. 1957-1959, 1999.

[76] P. R. Walden and H. N. Eisen, "Cognate peptides induce selfdestruction of CD8+ cytolytic T lymphocytes," Proceedings of the National Academy of Sciences of the United States of America, vol. 87, no. 22, pp. 9015-9019, 1990.

[77] E. Hanon, J. C. Stinchcombe, M. Saito et al., "Fracticide among CD8+ T lymphocytes naturally infected with human T cell lymphotropic virus type I," Immunity, vol. 13, no. 5, pp. 657-664, 2000.

[78] J. F. Huang, Y. Yang, H. Sepulveda et al., "TCR-mediated internalization of peptide-MHC complexes acquired by $\mathrm{T}$ cells," Science, vol. 286, no. 5441, pp. 952-954, 1999.

[79] L. Chen, M. Woo, R. Hakem, and R. G. Miller, "Perforindependent activation-induced cell death acts through caspase 3 but not through caspases 8 or 9," European Journal of Immunology, vol. 33, no. 3, pp. 769-778, 2003.

[80] S. Isaaz, K. Baetz, K. Olsen, E. Podack, and G. M. Griffiths, "Serial killing by cytotoxic T lymphocytes: $\mathrm{T}$ cell receptor triggers degranulation, re-filling of the lytic granules and secretion of lytic proteins via a non-granule pathway," European Journal of Immunology, vol. 25, no. 4, pp. 10711079, 1995.

[81] H. Ida, T. Nakashima, N. L. Kedersha et al., "Granzyme B leakage-induced cell death: a new type of activation-induced natural killer cell death," European Journal of Immunology, vol. 33, no. 12, pp. 3284-3292, 2003.

[82] C. E. Hirst, M. S. Buzza, C. H. Bird et al., "The intracellular granzyme B inhibitor, proteinase inhibitor 9 , is up-regulated during accessory cell maturation and effector cell degranulation, and its overexpression enhances CTL potency," Journal of Immunology, vol. 170, no. 2, pp. 805-815, 2003.

[83] T. Phillips, J. T. Opferman, R. Shah, N. Liu, C. J. Froelich, and P. G. Ashton-Rickardt, "A role for the granzyme B inhibitor serine protease inhibitor 6 in CD8 + memory cell homeostasis," Journal of Immunology, vol. 173, no. 6, pp. 3801-3809, 2004.

[84] M. Zhang, S. M. Park, Y. Wang et al., "Serine protease inhibitor 6 protects cytotoxic T cells from self-inflicted injury by ensuring the integrity of cytotoxic granules," Immunity, vol. 24, no. 4, pp. 451-461, 2006.

[85] M. Zhang, S. Byrne, N. Liu, Y. Wang, A. Oxenius, and P. G. Ashton-Rickardt, "Differential survival of cytotoxic T cells and memory cell precursors," Journal of Immunology, vol. 178, no. 6, pp. 3483-3491, 2007.
[86] M. A. Cannarile, N. A. Lind, R. Rivera et al., "Transcriptional regulator Id2 mediates CD8+ T cell immunity," Nature Immunology, vol. 7, no. 12, pp. 1317-1325, 2006.

[87] D. I. Godfrey, H. R. MacDonald, M. Kronenberg, M. J. Smyth, and L. Van Kaer, "NKT cells: what's in a name?" Nature Reviews Immunology, vol. 4, no. 3, pp. 231-237, 2004.

[88] A. Bendelac, P. B. Savage, and L. Teyton, "The biology of NKT cells," Annual Review of Immunology, vol. 25, pp. 297-336, 2007.

[89] A. W. Ansari, J. N. Temblay, S. H. Alyahya, and P. G. AshtonRickardt, "Serine protease inhibitor 6 protects iNKT cells from self-inflicted damage," Journal of Immunology, vol. 185, no. 2, pp. 877-883, 2010.

[90] J. Jacob and D. Baltimore, "Modelling T-cell memory by genetic marking of memory T cells in vivo," Nature, vol. 399, no. 6736, pp. 593-597, 1999.

[91] S. M. Kaech, S. Hemby, E. Kersh, and R. Ahmed, "Molecular and functional profiling of memory CD8 T cell differentiation," Cell, vol. 111, no. 6, pp. 837-851, 2002.

[92] N. Liu, T. Phillips, M. Zhang et al., "Serine protease inhibitor 2A is a protective factor for memory T cell development," Nature Immunology, vol. 5, no. 9, pp. 919-926, 2004.

[93] S. Forsyth, A. Horvath, and P. Coughlin, "A review and comparison of the murine $\alpha 1$-antitrypsin and $\alpha 1$ antichymotrypsin multigene clusters with the human clade A serpins," Genomics, vol. 81, no. 3, pp. 336-345, 2003.

[94] S. M. Byrne, A. Aucher, S. H. Alyahya et al., "Cathepsin B controls the persistence of memory CD8+ T cells," Journal of Immunology, vol. 189, no. 3, pp. 1133-1143, 2012.

[95] N. S. Joshi, W. Cui, A. Chandele et al., "Inflammation directs memory precursor and short-lived effector CD8+ T cell fates via the graded expression of T-bet transcription factor," Immunity, vol. 27, no. 2, pp. 281-295, 2007.

[96] S. Jung, D. Unutmaz, P. Wong et al., "In vivo depletion of $\mathrm{CD} 11 \mathrm{c}+$ dendritic cells abrogates priming of CD8+ T cells by exogenous cell-associated antigens," Immunity, vol. 17, no. 2, pp. 211-220, 2002.

[97] D. J. Zammit, L. S. Cauley, Q. M. Pham, and L. Lefrançois, "Dendritic cells maximize the memory CD8 T cell response to infection," Immunity, vol. 22, no. 5, pp. 561-570, 2005.

[98] G. T. Belz, C. M. Smith, D. Eichner et al., "Cutting edge: conventional CD $8 \alpha+$ dendritic cells are generally involved in priming CTL immunity to viruses," Journal of Immunology, vol. 172, no. 4, pp. 1996-2000, 2004.

[99] W. R. Heath, G. T. Belz, G. M. N. Behrens et al., "Crosspresentation, dendritic cell subsets, and the generation of immunity to cellular antigens," Immunological Reviews, vol. 199, pp. 9-26, 2004.

[100] I. F. Hermans, D. S. Ritchie, J. Yang, J. M. Roberts, and F. Ronchese, "CD8+ T cell-dependent elimination of dendritic cells in vivo limits the induction of antitumor immunity," Journal of Immunology, vol. 164, no. 6, pp. 3095-3101, 2000.

[101] J. Yang, S. P. Huck, R. S. McHugh, I. F. Hermans, and F. Ronchese, "Perforin-dependent elimination of dendritic cells regulates the expansion of antigen-specific CD8+ T cells in vivo," Proceedings of the National Academy of Sciences of the United States of America, vol. 103, no. 1, pp. 147-152, 2006.

[102] L. M. Wakim, J. Waithman, N. Van Rooijen, W. R. Heath, and F. R. Carbone, "Dendritic cell-induced memory T cell activation in nonlymphoid tissues," Science, vol. 319, no. 5860, pp. 198-202, 2008.

[103] P. Wong and E. G. Pamer, "Feedback regulation of pathogenspecific T cell priming," Immunity, vol. 18, no. 4, pp. 499$511,2003$. 
[104] J. P. Medema, J. De Jong, L. T. C. Peltenburg et al., "Blockade of the granzyme $\mathrm{B} /$ perforin pathway through overexpression of the serine protease inhibitor PI-9/SPI-6 constitutes a mechanism for immune escape by tumors," Proceedings of the National Academy of Sciences of the United States of America, vol. 98, no. 20, pp. 11515-11520, 2001.

[105] E. Lovo, M. Zhang, L. Wang, and P. G. Ashton-Rickardt, "Serine protease inhibitor 6 is required to protect dendritic cells from the kiss of death," Journal of Immunology, vol. 188, no. 3, pp. 1057-1063, 2012.

[106] T. A. Graubert, J. F. DiPersio, J. H. Russell, and T. J. Ley, "Perforin/granzyme-dependent and independent mechanisms are both important for the development of graftversus-host disease after murine bone marrow transplantation," Journal of Clinical Investigation, vol. 100, no. 4, pp. 904911, 1997.

[107] Y. Miura, C. J. Thoburn, E. C. Bright, and A. D. Hess, "Cytolytic effector mechanisms and gene expression in autologous graft-versus-host disease: distinct roles of perforin and Fas ligand," Biology of Blood and Marrow Transplantation, vol. 10, no. 3, pp. 156-170, 2004.

[108] R. Goldbach-Mansky, S. Suson, R. Wesley, C. E. Hack, H. S. El-Gabalawy, and P. P. Tak, "Raised granzyme B levels are associated with erosions in patients with early rheumatoid factor positive rheumatoid arthrits," Annals of the Rheumatic Diseases, vol. 64, no. 5, pp. 715-721, 2005.

[109] M. C. Kraan, J. J. Haringman, H. Weedon et al., "T cells, fibroblast-like synoviocytes, and granzyme B+ cytotoxic cells are associated with joint damage in patients with recent onset rheumatoid arthritis," Annals of the Rheumatic Diseases, vol. 63, no. 5, pp. 483-488, 2004.

[110] J. C. Choy, R. P. Cruz, A. Kerjner et al., "Granzyme $\mathrm{B}$ induces endothelial cell apoptosis and contributes to the development of transplant vascular disease," American Journal of Transplantation, vol. 5, no. 3, pp. 494-499, 2005.

[111] J. C. Choy, P. C. McDonald, A. C. Suarez et al., "Granzyme B in atherosclerosis and transplant vascular disease: association with cell death and atherosclerotic disease severity," Modern Pathology, vol. 16, no. 5, pp. 460-470, 2003.

[112] D. Jenkins, R. Seth, J. A. Kummer, B. B. Scott, C. J. Hawkey, and R. A. Robins, "Differential levels of granzyme $\mathrm{B}$, regulatory cytokines, and apoptosis in Crohn's disease and ulcerative colitis at first presentation," Journal of Pathology, vol. 190, no. 2, pp. 184-189, 2000.

[113] C. G. Bien, J. Bauer, T. L. Deckwerth et al., "Destruction of neurons by cytotoxic T cells: a new pathogenic mechanism in Rasmussen's encephalitis," Annals of Neurology, vol. 51, no. 3, pp. 311-318, 2002.

[114] P. Blanco, V. Pitard, J. F. Viallard, J. L. Taupin, J. L. Pellegrin, and J. F. Moreau, "Increase in activated CD8+ T lymphocytes expressing perforin and granzyme B correlates with disease activity in patients with systemic lupus erythematosus," Arthritis and Rheumatism, vol. 52, no. 1, pp. 201-211, 2005.

[115] B. A. Bladergroen, M. C. M. Strik, A. M. Wolbink et al., "The granzyme B inhibitor proteinase inhibitor 9 (PI9) is expressed by human mast cells," European Journal of Immunology, vol. 35, no. 4, pp. 1175-1183, 2005.

[116] B. A. Bladergroen, M. C. M. Strik, N. Bovenschen et al., "The granzyme B inhibitor, protease inhibitor 9, is mainly expressed by dendritic cells and at immune-privileged sites," Journal of Immunology, vol. 166, no. 5, pp. 3218-3225, 2001.

[117] J. L. Young, G. K. Sukhova, D. Foster, W. Kisiel, P. Libby, and U. Schönbeck, "The serpin proteinase inhibitor 9 is an endogenous inhibitor of interleukin $1 \beta$-converting enzyme (caspase-1) activity in human vascular smooth muscle cells," Journal of Experimental Medicine, vol. 191, no. 9, pp. 15351544, 2000.

[118] L. T. Quan, A. Caputo, R. C. Bleackley, D. J. Pickup, and G. S. Salvesen, "Granzyme B is inhibited by the cowpox virus serpin cytokine response modifier A," Journal of Biological Chemistry, vol. 270, no. 18, pp. 10377-10379, 1995.

[119] J. L. Macen, R. S. Garner, P. Y. Musy et al., "Differential inhibition of the Fas- and granule-mediated cytolysis pathways by the orthopoxvirus cytokine response modifier A/SPI-2 and SPI-1 protein," Proceedings of the National Academy of Sciences of the United States of America, vol. 93, no. 17, pp. 9108-9113, 1996.

[120] B. A. Bladergroen, C. J. L. M. Meijer, R. L. Ten Berge et al., "Expression of the granzyme B inhibitor, protease inhibitor 9, by tumor cells in patients with non-Hodgkin and Hodgkin lymphoma: a novel protective mechanism for tumor cells to circumvent the immune system?" Blood, vol. 99, no. 1, pp. 232-237, 2002.

[121] R. L. Ten Berge, C. J. L. M. Meijer, D. F. Dukers et al., "Expression levels of apoptosis-related proteins predict clinical outcome in anaplastic large cell lymphoma," Blood, vol. 99, no. 12, pp. 4540-4546, 2002.

[122] J. W. Fisher, S. Koury, T. Ducey, and S. Mendel, "Erythropoietin production by interstitial cells of hypoxic monkey kidneys," British Journal of Haematology, vol. 95, no. 1, pp. 27-32, 1996.

[123] D. M. Wojchowski, P. Sathyanarayana, and A. Dev, "Erythropoietin receptor response circuits," Current Opinion in Hematology, vol. 17, no. 3, pp. 169-176, 2010.

[124] H. Wu, X. Liu, R. Jaenisch, and H. F. Lodish, "Generation of committed erythroid BFU-E and CFU-E progenitors does not require erythropoietin or the erythropoietin receptor," Cell, vol. 83, no. 1, pp. 59-67, 1995.

[125] A. C. Johansson, H. Appelqvist, C. Nilsson, K. Kågedal, K. Roberg, and K. Öllinger, "Regulation of apoptosis-associated lysosomal membrane permeabilization," Apoptosis, vol. 15, no. 5, pp. 527-540, 2010.

[126] R. Blomgran, L. Zheng, and O. Stendahl, "Cathepsin-cleaved Bid promotes apoptosis in human neutrophils via oxidative stress-induced lysosomal membrane permeabilization," Journal of Leukocyte Biology, vol. 81, no. 5, pp. 1213-1223, 2007.

[127] E. Fibach and E. A. Rachmilewitz, "The role of antioxidants and iron chelators in the treatment of oxidative stress in thalassemia," Annals of the New York Academy of Sciences, vol. 1202, pp. 10-16, 2010.

[128] C. J. Luckey, D. Bhattacharya, A. W. Goldrath, I. L. Weissman, C. Benoist, and D. Mathis, "Memory T and memory B cells share a transcriptional program of self-renewal with longterm hematopoietic stem cells," Proceedings of the National Academy of Sciences of the United States of America, vol. 103, no. 9, pp. 3304-3309, 2006.

[129] J. P. Medema, D. H. Schuurhuis, D. Rea et al., "Expression of the serpin serine protease inhibitor 6 protects dendritic cells from cytotoxic T lymphocyte-induced apoptosis: differential modulation by $\mathrm{T}$ helper type 1 and type 2 cells," Journal of Experimental Medicine, vol. 194, no. 5, pp. 657-667, 2001.

[130] D. E. Hassett, M. K. Slifka, J. Zhang, and J. L. Whitton, "Direct ex vivo kinetic and phenotypic analyses of CD8+ Tcell responses induced by DNA immunization," Journal of Virology, vol. 74, no. 18, pp. 8286-8291, 2000.

[131] J. Rice, M. L. Dossett, C. Öhlén et al., “DNA fusion gene vaccination mobilizes effective anti-leukemic cytotoxic 
T lymphocytes from a tolerized repertoire," European Journal of Immunology, vol. 38, no. 8, pp. 2118-2130, 2008.

[132] J. N. Radcliffe, J. S. Roddick, F. K. Stevenson, and S. M. Thirdborough, "Prolonged antigen expression following DNA vaccination impairs effector $\mathrm{CD} 8+\mathrm{T}$ cell function and memory development," Journal of Immunology, vol. 179, no. 12, pp. 8313-8321, 2007.

[133] T. W. Kim, C. F. Hung, D. A. K. Boyd et al., "Enhancement of DNA vaccine potency by coadministration of a tumor antigen gene and DNA encoding serine protease inhibitor-6," Cancer Research, vol. 64, no. 1, pp. 400-405, 2004.

[134] N. El Haddad, D. Heathcote, R. Moore et al., "Mesenchymal stem cells express serine protease inhibitor to evade the host immune response," Blood, vol. 117, no. 4, pp. 1176-1183, 2011.

[135] N. El Haddad, R. Moore, D. Heathcote et al., "The novel role of SERPINB9 in cytotoxic protection of human mesenchymal stem cells," Journal of Immunology, vol. 187, no. 5, pp. 22522260, 2011.

[136] C. G. Bien, G. Widman, H. Urbach et al., "The natural history of Rasmussen's encephalitis," Brain, vol. 125, no. 8, pp. 17511759, 2002.

[137] A. T. Rowshani, S. Florquin, F. Bemelman, J. A. Kummer, C. E. Hack, and I. J. M. Ten Berge, "Hyperexpression of the granzyme B inhibitor PI-9 in human renal allografts: a potential mechanism for stable renal function in patients with subclinical rejection," Kidney International, vol. 66, no. 4, pp. 1417-1422, 2004.

[138] L. Del Vecchio, A. Cavalli, B. Tucci, and F. Locatelli, "Chronic kidney disease-associated anemia: new remedies," Current Opinion in Investigational Drugs, vol. 11, no. 9, pp. 10301038, 2010.

[139] M. Dicato and L. Plawny, "Erythropoietin in cancer patients: pros and cons," Current Opinion in Oncology, vol. 22, no. 4, pp. 307-311, 2010.

[140] D. J. Buttle, M. Murata, C. G. Knight, and A. J. Barrett, "CA074 methyl ester: a proinhibitor for intracellular cathepsin B," Archives of Biochemistry and Biophysics, vol. 299, no. 2, pp. 377-380, 1992.

[141] J. L. Spivak, P. Gascón, and H. Ludwig, "Anemia management in oncology and hematology," The Oncologist, vol. 14, supplement 1, pp. 43-56, 2009.

[142] H. Schmid and H. Schiffl, "Erythropoiesis stimulating agents and anaemia of end-stage renal disease," Cardiovascular and Hematological Agents in Medicinal Chemistry, vol. 8, no. 3, pp. 164-172, 2010.

[143] T. Willinger, T. Freeman, H. Hasegawa, A. J. McMichael, and M. F. C. Callan, "Molecular signatures distinguish human central memory from effector memory CD8 T cell subsets," Journal of Immunology, vol. 175, no. 9, pp. 5895-5903, 2005.

[144] S. Halfon, J. Ford, J. Foster et al., "Leukocystatin, a new class II cystatin expressed selectively by hematopoietic cells," Journal of Biological Chemistry, vol. 273, no. 26, pp. 1640016408, 1998.

[145] C. A. Willoughby, H. G. Bull, M. Garcia-Calvo, J. Jiang, K. T. Chapman, and N. A. Thornberry, "Discovery of potent, selective human granzyme B inhibitors that inhibit CTL mediated apoptosis," Bioorganic and Medicinal Chemistry Letters, vol. 12, no. 16, pp. 2197-2200, 2002. 


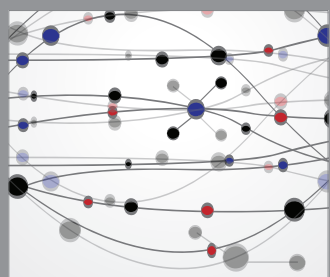

The Scientific World Journal
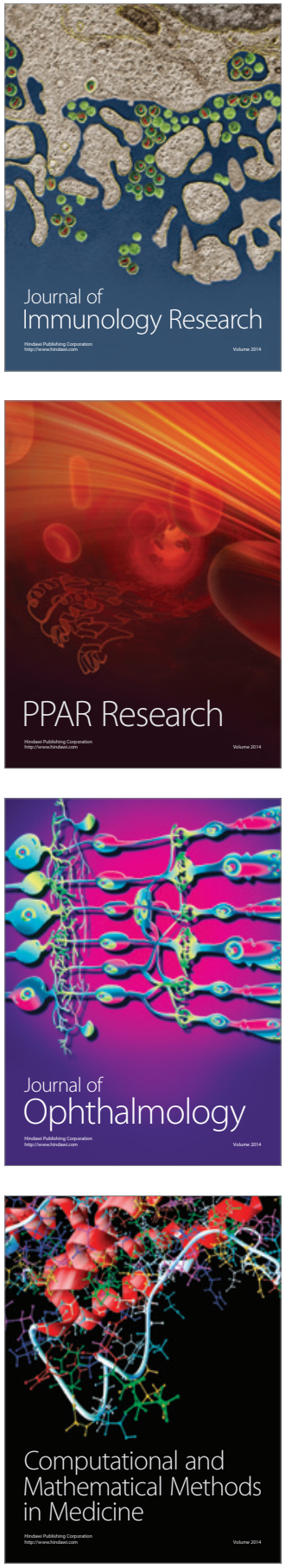

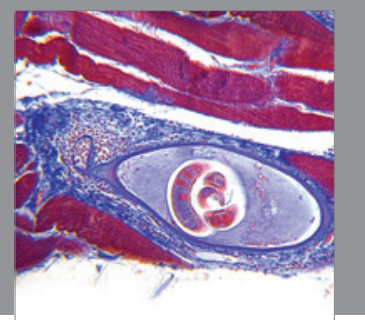

Gastroenterology

Research and Practice
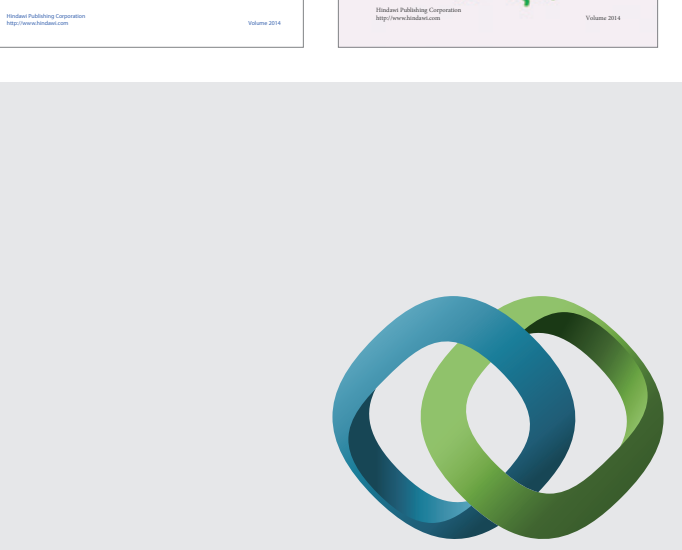

\section{Hindawi}

Submit your manuscripts at

http://www.hindawi.com
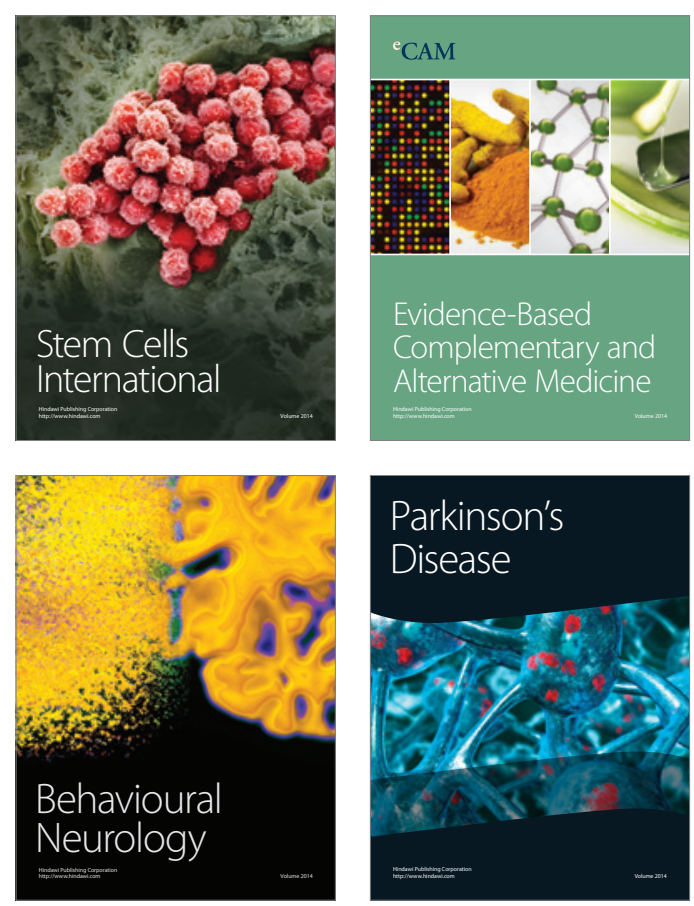

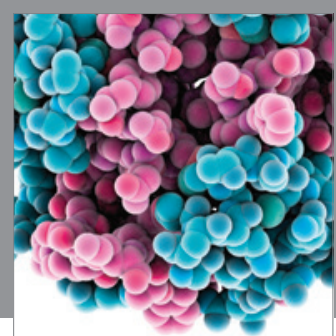

Journal of
Diabetes Research

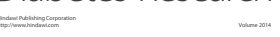

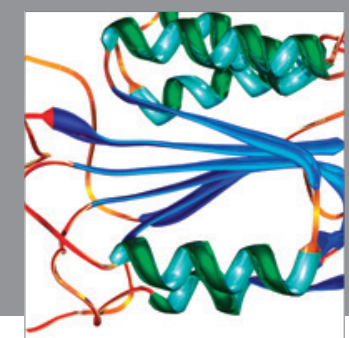

Disease Markers
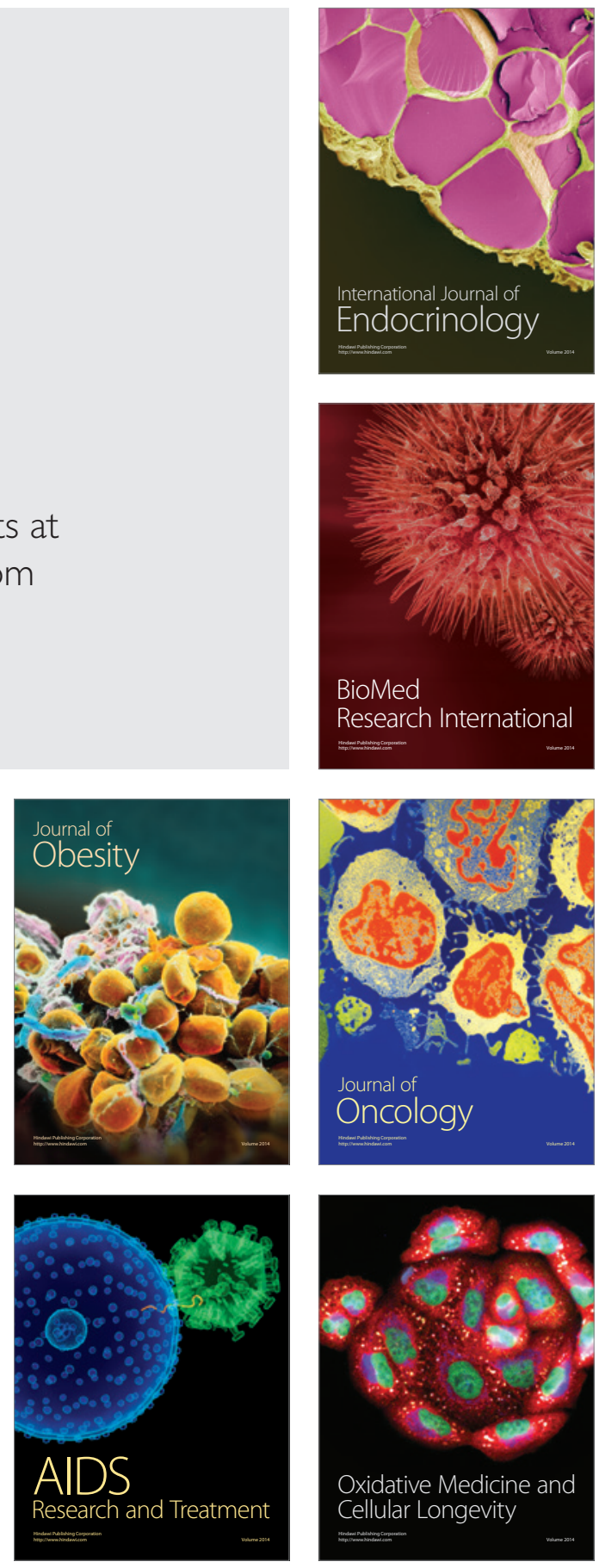